\title{
Calibration of a large-scale hydrological model using satellite-based soil moisture and evapotranspiration products
}

\author{
Patricia López López ${ }^{1,2}$, Edwin H. Sutanudjaja ${ }^{2}$, Jaap Schellekens ${ }^{1}$, Geert Sterk ${ }^{2}$, and Marc F. P. Bierkens ${ }^{2,3}$ \\ ${ }^{1}$ Inland Water Systems Unit, Deltares, Delft, the Netherlands \\ ${ }^{2}$ Department of Physical Geography, Faculty of Geosciences, Utrecht University, Utrecht, the Netherlands \\ ${ }^{3}$ Subsurface and Groundwater Systems Unit, Deltares, Utrecht, the Netherlands \\ Correspondence to: Patricia López López (patricia.lopez@ deltares.nl)
}

Received: 13 January 2017 - Discussion started: 16 January 2017

Revised: 22 May 2017 - Accepted: 29 May 2017 - Published: 29 June 2017

\begin{abstract}
A considerable number of river basins around the world lack sufficient ground observations of hydrometeorological data for effective water resources assessment and management. Several approaches can be developed to increase the quality and availability of data in these poorly gauged or ungauged river basins; among them, the use of Earth observations products has recently become promising. Earth observations of various environmental variables can be used potentially to increase knowledge about the hydrological processes in the basin and to improve streamflow model estimates, via assimilation or calibration. The present study aims to calibrate the large-scale hydrological model PCRaster GLOBal Water Balance (PCR-GLOBWB) using satellite-based products of evapotranspiration and soil moisture for the Moroccan Oum er Rbia River basin. Daily simulations at a spatial resolution of $5 \times 5$ arcmin are performed with varying parameters values for the 32-year period 19792010. Five different calibration scenarios are inter-compared: (i) reference scenario using the hydrological model with the standard parameterization, (ii) calibration using in situobserved discharge time series, (iii) calibration using the Global Land Evaporation Amsterdam Model (GLEAM) actual evapotranspiration time series, (iv) calibration using ESA Climate Change Initiative (CCI) surface soil moisture time series and (v) step-wise calibration using GLEAM actual evapotranspiration and ESA CCI surface soil moisture time series. The impact on discharge estimates of precipitation in comparison with model parameters calibration is investigated using three global precipitation products, including ERA-Interim (EI), WATCH Forcing methodology applied to ERA-Interim reanalysis data (WFDEI) and Multi-
\end{abstract}

Source Weighted-Ensemble Precipitation data by merging gauge, satellite and reanalysis data (MSWEP).

Results show that GLEAM evapotranspiration and ESA CCI soil moisture may be used for model calibration resulting in reasonable discharge estimates (NSE values from 0.5 to 0.75 ), although better model performance is achieved when the model is calibrated with in situ streamflow observations. Independent calibration based on only evapotranspiration or soil moisture observations improves model predictions to a lesser extent. Precipitation input affects discharge estimates more than calibrating model parameters. The use of WFDEI precipitation leads to the lowest model performances. Apart from the in situ discharge calibration scenario, the highest discharge improvement is obtained when EI and MSWEP precipitation products are used in combination with a step-wise calibration approach based on evapotranspiration and soil moisture observations. This study opens up the possibility of using globally available Earth observations and reanalysis products of precipitation, evapotranspiration and soil moisture in large-scale hydrological models to estimate discharge at a river basin scale.

\section{Introduction}

To assess and manage the water resources available within a river basin, good estimates of hydro-meteorological data, such as precipitation, temperature and streamflow, are required. However, many river basins around the world still have a limited number of in situ observations, being either ungauged (Sivapalan et al., 2003) or poorly gauged 
(Loukas and Vasiliades, 2014). Ungauged or poorly gauged river basins also include those basins where data are inaccurate, scarce, intermittent or collected at different temporal resolutions, leading to the problem that it is not clear how to integrate these data consistently into hydrological models (Winsemius et al., 2009). As a result, the limited availability and poor quality of data induces large uncertainty in model outputs from these river basins (Seibert and Beven, 2009). Developing novel strategies to enhance available data sets and hydrological models is one of the key strategies when working in ungauged basins (Hrachowitz et al., 2013).

To overcome the lack of hydro-meteorological data, a promising approach is the use of the recently developed global Earth observations and reanalysis products to supplement the available data. In the last few decades, radar and satellite technologies have improved and have become more broadly available, providing diverse hydro-meteorological data sets at finer spatial and temporal resolutions: precipitation (Joyce et al., 2004; Huffman et al., 2007), soil moisture (Njoku et al., 2003; Dorigo et al., 2015), total water storage (Tapley et al., 2004), evapotranspiration (Bastiaanssen et al., 1998; Nishida, 2003; Miralles et al., 2011b), etc.

Previous studies have demonstrated the possibility of using these global data sets to better understand the hydrological processes in a river catchment (Kite and Droogers, 2000; Vereecken et al., 2008; Seneviratne et al., 2010; Hafeez et al., 2011) and to improve streamflow model estimates through assimilation (Parajka et al., 2006; Roy et al., 2010; Brocca et al., 2012; Thirel et al., 2013; López López et al., 2016) and/or calibration techniques or a priori determination of model parameters (Jacobs et al., 2003; Beck et al., 2009). Calibration approaches based on multiple remotely sensed variables have some advantages in comparison with traditional calibration approaches using only observed and modelled hydrographs in a limited number of locations. Fenicia et al. (2007) and Gupta et al. (2008) recognized that traditional calibration may lead to over-parameterization, i.e. similar model results are obtained with a combination of multiple parameters, whereas calibrating for multiple variables - step-wise calibration - may partly resolve the problem of non-uniqueness and provides a better understanding of the processes happening within the catchment.

Several studies have investigated calibration approaches based on variables different than streamflow. Campo et al. (2006) used soil moisture information radar images from ERS-2 sensors to parameterize the hydrological model MOBIDIC (MOdello di Bilancio Idrologico DIstribuito e Continuo). Immerzeel and Droogers (2008) the hydrological model SWAT (Soil and Water Assessment Tool) based on satellite evapotranspiration from MODIS satellite images. Lo et al. (2010) improved the parameter estimation of the Community Land Model 3.0 using GRACE total water storage data, while Isenstein et al. (2015) calibrated the hydrological model VIC (Variable Infiltration Capacity) using snow covered area from MODIS satellite data. Others have combined remotely sensed variables with in situ streamflow observations for calibration. In Rientjes et al. (2013), the model HBV (Hydrologiska Byråns Vattenbalansavdelning) model was calibrated with satellite-based evapotranspiration from MODIS and streamflow. Wanders et al. (2014) calibrated model parameters of LISFLOOD based on discharge and soil moisture observations acquired by the AMSR-E, SMOS and ASCAT instruments, while Sutanudjaja et al. (2014) calibrated the large-scale model PCR-GLOBWB using streamflow and soil water index information derived from the ERS scatterometers. At a global scale, Beck et al. (2016) used parameter regionalization to calibrate an HBV model. However, the simultaneous use of more than one environmental variable different than streamflow for calibration is rare. A calibration approach using different variables, independently and in combination with streamflow observations, may further improve model performance and contribute to a better understanding of hydrological processes. In the present study, this is tested by comparing multiple calibration scenarios based on evapotranspiration, soil moisture and discharge data.

The previously mentioned calibration experiments were performed for well-studied river basins, such as the RhineMeuse river basin, with good coverage of in situ hydrometeorological data. In the present study area, the Oum er Rbia River basin located in Morocco, ground observations are spatially sparse and limited in number, classifying it as a poorly gauged river basin. The region frequently suffers from water scarcity and droughts and water availability is the main factor influencing socio-economic development, mostly driven by agriculture (Houdret, 2008). The studies of Tramblay et al. (2012), Tramblay et al. (2016) and Ouatiki et al. (2017) are testimony to the relevance of this area. Therefore, developing new strategies to model this watershed is highly relevant to improve water management and assessment of the water availability within the basin.

This study aims to calibrate a large-scale hydrological model, PCR-GLOBWB 2.0 (Sutanudjaja et al., 2016; Sutanudjaja et al., 2017), using soil moisture and evapotranspiration observations alone and to compare its discharge estimates to those obtained when the model is traditionally calibrated to streamflow data. We use the evapotranspiration product generated by an enhanced version of the Global Land Evaporation Amsterdam Model (GLEAM v3.0; Martens et al., 2016b) in combination with the surface soil moisture product from the ESA Climate Change Initiative (CCI; Dorigo et al., 2015). Both products are derived from satellite data. Furthermore, the influence of precipitation forcing is considered and three different global precipitation products are used and inter-compared: ERA-Interim reanalysis data (EI; Dee et al., 2011), WATCH Forcing Data methodology applied to ERA-Interim reanalysis data (WFDEI; Weedon et al., 2014) and Multi-Source Weighted-Ensemble Precipitation data by merging gauge, satellite and reanalysis data (MSWEP; Beck et al., 2017b). 
Five different calibration approaches are performed by using five calibration scenarios that include streamflow, soil moisture and evapotranspiration: (i) reference scenario using the hydrological model with the standard parameterization, (ii) calibration using in situ-observed discharge time series, (iii) calibration using GLEAM actual evapotranspiration time series, (iv) calibration using ESA CCI surface soil moisture time series and (v) step-wise calibration using GLEAM actual evapotranspiration and ESA CCI surface soil moisture time series. The above is repeated for each of the selected global precipitation products. A priori, it is expected that calibrating to streamflow observations yields the best discharge estimates, and that the step-wise calibration using soil moisture and evapotranspiration provides better results than the calibration scenarios based only on soil moisture or evapotranspiration.

The novel aspects and new contributions of this work include the use and comparison of three different and recently generated global precipitation products, the exploration of calibration techniques based on Earth observations of soil moisture and evapotranspiration and their application in a large-scale hydrological model to provide streamflow estimates in the ungauged Oum er Rbia River basin. Furthermore, understanding the potential gain of calibrating largescale models with remotely sensed observations may have benefits for water resources management in data-poor river basins globally.

This paper first describes the study area, then the methodology, including the hydrological model, data, calibration and validation strategy and performance metrics. Subsequently, results are presented, starting with the intercomparison of precipitation products and following with calibration and validation results. The paper ends with discussion and conclusions.

\section{Study area}

The study area is the Oum er Rbia River basin, which is situated in the central-western region of Morocco between the Atlas Mountains to the south and the Mesetian zone to the north, flowing into the Atlantic Ocean (Fig. 1). The basin's topography ranges from $2800 \mathrm{~m}$ in the southern upstream zone to $150 \mathrm{~m}$ in the northern downstream zone. The Oum er Rbia is the second largest river in Morocco with a total length of $550 \mathrm{~km}$ and it drains an area of approximately $38025 \mathrm{~km}^{2}$.

The climate in the coastal and mountainous areas is Mediterranean, characterized with high temperatures in the summer and warm autumn and winter months with rainfall, and semi-arid in the central plain (Jones et al., 2013). Precipitation increases from downstream to upstream areas in the mountains. The mean annual precipitation and temperature are $400 \mathrm{~mm}$ and $18^{\circ} \mathrm{C}$, respectively. Approximately 70 to $80 \%$ of the annual rainfall is concentrated in the period from October to May.
The lowlands of the basin are mainly covered with rainfed and irrigated agriculture fields and the upstream regions are a combination of Mediterranean forests, woodlands and scrub. The geology of the area is mostly composed of limestone, marl and sandstone with a karst aquifer in the Atlas Mountains and a multi-layered system of superficial and deep aquifers in the western plains (Bouchaou et al., 2009).

\section{Methodology}

\subsection{Large-scale hydrological model: PCR-GLOBWB}

The large-scale hydrological model PCR-GLOBWB 2.0 (Sutanudjaja et al., 2016, 2017) was used at a spatial resolution of $5 \times 5$ arcmin (approximately $10 \times 10 \mathrm{~km}$ at the equator) and at a daily temporal resolution. PCR-GLOBWB is a leaky-bucket type of model applied on a cell-by-cell basis. Figure 2 illustrates a schematic representation of the structure of PCR-GLOBWB model. For each grid cell and time step, the model determines the water balance considering the following water storage components: soil moisture, groundwater, surface water, interception storage and snow. The soil is divided into three vertical layers representing the top $5 \mathrm{~cm}$ of soil (depth $Z_{1} \leq 5 \mathrm{~cm}$ ), the following $25 \mathrm{~cm}$ of soil (depth $Z_{2} \leq 30 \mathrm{~cm}$ ) and the remaining $120 \mathrm{~cm}$ of soil (depth $Z_{3} \leq 150 \mathrm{~cm}$ ), in which the stores are symbolized as $S_{1}, S_{2}$ and $S_{3}$, respectively. The underlying groundwater store $\left(S_{4}\right)$ consists of two layers: an active or renewable layer and a non-active or non-renewable layer of fossil water, in which the stores are symbolized as $S_{4 \text { act }}$ and $S_{4 \text { fos }}$, respectively. The model also includes the water exchange processes between the top layer and the atmosphere (precipitation, evapotranspiration and snowmelt), among the soil layers (percolation and capillary rise) and between the soil layers and the active layer of the groundwater store (groundwater recharge, discharge to baseflow and capillary rise). Each grid cell is divided into sub-grids considering variations of elevation, vegetation, soil and land cover. Five land cover types are distinguished: irrigated paddy field, irrigated non-paddy field, grassland (short natural vegetation), forest (tall natural vegetation) and open water. To compute the total runoff of every grid cell, the model includes direct runoff $\left(Q_{\mathrm{DR}}\right)$, shallow sub-surface flow from the third soil layer $\left(Q_{\mathrm{SF}}\right)$ and baseflow from the active groundwater layer $\left(Q_{\mathrm{BF}}\right)$. The total runoff is accumulated from all grid cells and routed along the drainage network to obtain the river discharge ( $\left.Q_{\text {channel }}\right)$. The PCRGLOBWB model version used here (Sutanudjaja et al., 2016) simulates water availability and water abstraction, including reservoirs and domestic, industrial, livestock and irrigational water demands. The following subsections briefly describe the model components and the parameters relevant for the present calibration study. The reader is referred to Sutanudjaja et al. (2011) and Sutanudjaja et al. (2014) for a more detailed explanation. 


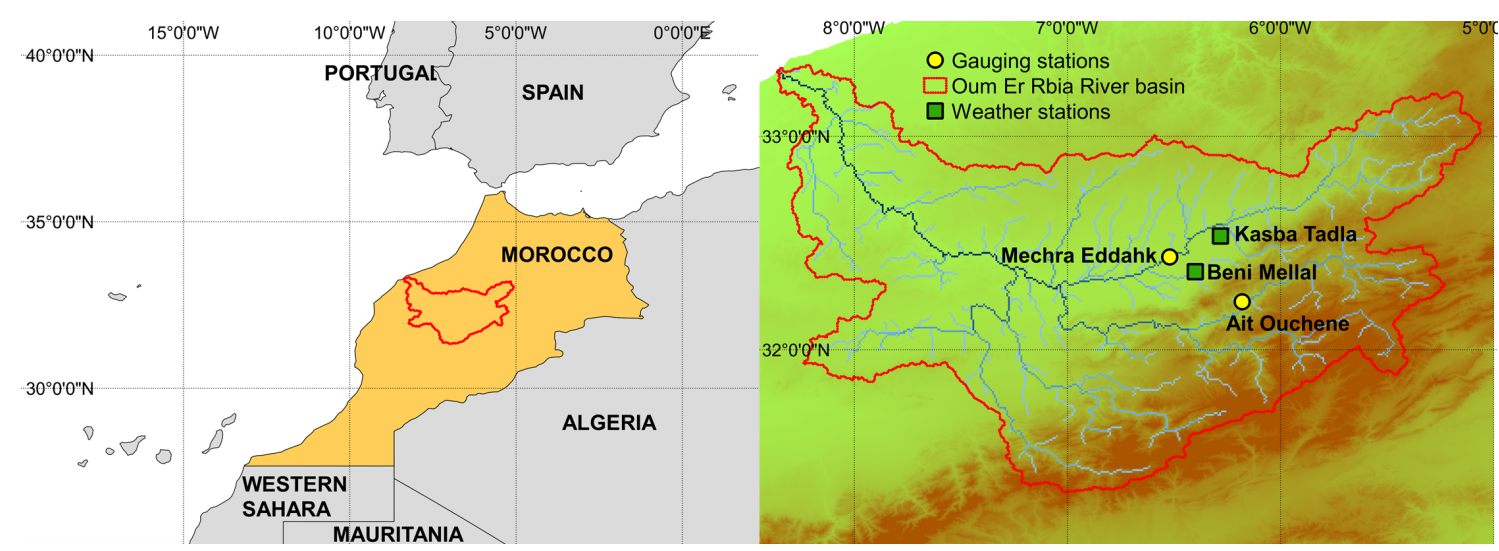

Figure 1. Oum er Rbia River basin and its location in Morocco (the delineation of the catchment is physically based). Yellow points represent the gauging stations and green squares represent the weather stations.

\subsubsection{Direct or surface runoff}

The amount of water that goes into the soil is the net precipitation $\left(P_{\mathrm{n}}\right)$ resulting from the surplus of precipitation above the interception capacity and the excess melt water from the snow pack. Net precipitation is partitioned into direct runoff $\left(Q_{\mathrm{DR}}\right)$ and net infiltration to the first soil layer $\left(P_{01}\right)$. The partitioning is done using the Improved Arno Scheme (Hagemann and Gates, 2003), in which the fraction of saturated soil of a cell is estimated based on the cell-minimum capacity $\left(W_{\min }\right)$, the cell-average actual storage ( $\left.W_{\text {act }}=S_{1}+S_{2}+S_{3}\right)$ and the water capacity for the entire soil profile $\left(W_{\max }=\mathrm{SC}_{1}+\mathrm{SC}_{2}+\mathrm{SC}_{3}, \mathrm{SC}_{\mathrm{n}}\right.$ : soil water capacity for layer $n$ ). If $W_{\min }=0$, direct runoff always occurs for a rainfall event. If $W_{\min }>0$, an event $P_{\mathrm{n}}$ only generates runoff $Q_{\mathrm{DR}}$ if $W_{\text {act }}>W_{\min }$. Cell-minimum capacity is therefore an important parameter which governs runoff generation response time.

\subsubsection{Vertical water exchanges between soil and groundwater stores and shallow sub-surface flow}

Net infiltration water into the first soil layer $\left(P_{01}\right)$ is transferred through the remaining soil layers. Vertical water exchanges occur between the first and the second layers $\left(P_{12}\right)$, between the second and the third layers $\left(P_{23}\right)$ and between the third soil layer and the active layer of the groundwater store $\left(P_{34}\right)$. Layers $P_{12}, P_{23}$ and $P_{34}$ consist of downward percolation and upward capillary rise, which depend on the degree of saturation $\left(s_{1}=S_{1} / \mathrm{SC}_{1}, s_{2}=S_{2} / \mathrm{SC}_{2}\right.$ and $s_{3}=S_{3} / \mathrm{SC}_{3}$ ) and the unsaturated hydraulic conductivity of each soil layer $\left(K_{\text {sat1 }}, K_{\text {sat2 }}\right.$ and $\left.K_{\text {sat3 } 3}\right)$. If $s_{1}>s_{2}$, percolation is equal to $K_{\text {sat1 }}$, whereas if $s_{2}>s_{1}$, capillary rise is equal to $K_{\text {sat } 2} \times\left(1-s_{1}\right)$, with $1-s_{1}$ the moisture deficit in the first soil layer. Layers $K_{\text {sat } 1}, K_{\text {sat2 }}$ and $K_{\text {sat3 }}$ controls the vertical fluxes between the soil layers and the groundwater store which affect significantly to the ground water recharge.
Moreover, $K_{\text {sat3 }}$ influences the shallow sub-surface flow from the third soil layer $\left(Q_{\mathrm{IF}}\right)$.

\subsubsection{Baseflow}

The last component that contributes to the total runoff for each grid cell is the baseflow from the active groundwater layer $\left(Q_{\mathrm{BF}}\right)$. This is calculated as $Q_{\mathrm{BF}}=S_{4 \text { act }} \times J$, where $J$ is the baseflow recession coefficient and depends on the aquifer transmissivity and the aquifer specific yield. Therefore, $J$ controls the direct contribution of groundwater store to the total runoff and hence to the river discharge.

\subsubsection{Evapotranspiration}

Actual evapotranspiration consist of transpiration $\left(E_{\mathrm{t}}\right)$, bare soil evaporation from the top soil layer $\left(E_{\mathrm{b}}\right)$, open-water evaporation $\left(E_{\mathrm{w}}\right)$, interception loss $\left(E_{\mathrm{i}}\right)$ and evaporation from the melt water store in the snow pack $\left(E_{\mathrm{s}}\right)$. Each evapotranspiration component is calculated based on the reference potential evapotranspiration $\left(E_{\mathrm{p}, 0}\right)$ and the corresponding factor coefficients related to vegetation cover fraction, crop and land cover type, surface water bodies, water stress and the interception flux.

\subsection{Data}

\subsubsection{Meteorological data}

The meteorological data required to force PCR-GLOBWB are air temperature, precipitation and reference potential evapotranspiration. Air temperature and precipitation were obtained from the WATCH Forcing Data methodology applied to ERA-Interim reanalysis data (WFDEI) at an original spatial resolution of $0.5^{\circ} \times 0.5^{\circ}$ (Weedon et al., 2014). Reference potential evapotranspiration was obtained through the obtained through the FAO (Food and Agriculture Organization) Penman-Monteith equation. Precipitation, air temperature and reference potential evapotranspiration were down- 


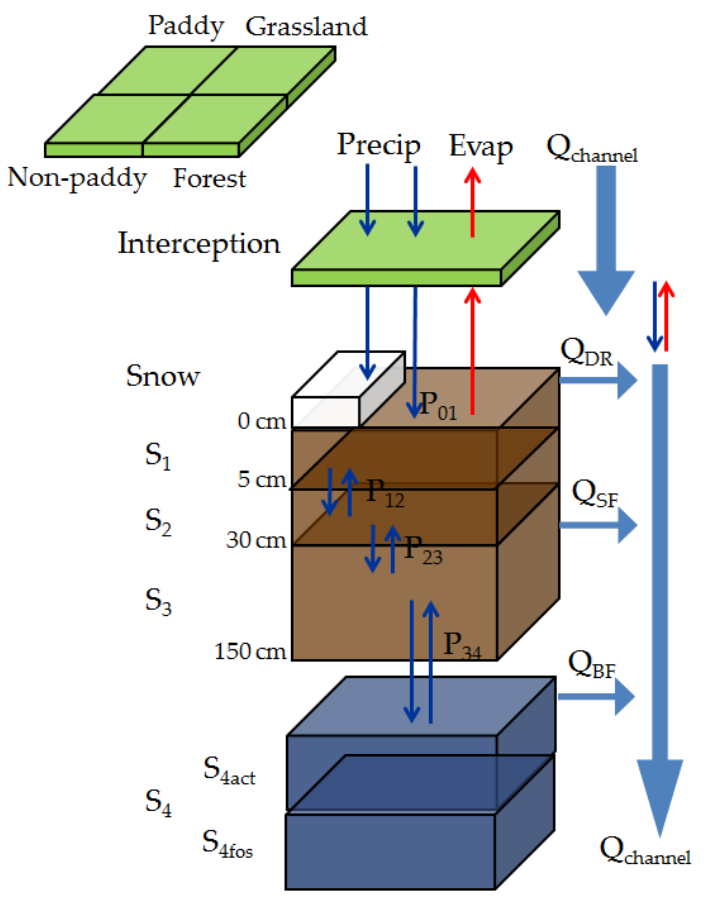

Figure 2. PCR-GLOBWB model structure, adapted from van Beek et al. (2011).

scaled from the original spatial resolution to a $0.08^{\circ} \times 0.08^{\circ}$ grid. Precipitation and air temperature were downscaled using precipitation and temperature lapse rates derived from the 10' CRU-CL2.0 data (New et al., 2002) through linear regression analysis (Sutanudjaja et al., 2011). Reference potential evapotranspiration was downscaled using the E2O (eartH2Observe) downscaling tools (Weiland et al., 2015; Schellekens and Weiland, 2017).

To test model sensitivity to precipitation, air temperature and reference potential evapotranspiration were fixed and two additional global precipitation products were used: (i) ERA-Interim reanalysis data (EI) from the European Centre for Medium-range Weather Forecasts (ECMWF) at the original spatial resolution of $0.5^{\circ} \times 0.5^{\circ}$ (Dee et al., 2011) and (ii) Multi-Source Weighted-Ensemble Precipitation data (MSWEP) by merging gauge, satellite and reanalysis data at the original spatial resolution of $0.25^{\circ} \times 0.25^{\circ}$ (Beck et al., 2017b).

The three global precipitation products were intercompared and interpolated to the two weather station locations found inside the Oum er Rbia basin (http://www.wmo. int/pages/themes/climate/): Beni Mellal and Kasba Tadla (Fig. 1). Kling-Gupta efficiency (KGE), Nash-Sutcliffe efficiency (NSE), Pearson's correlation coefficient $(r)$ and percent bias (PBias) between the interpolated and in situ ground daily data were calculated. A description of the performance metrics with their mathematical formulation is included in Sect. 3.4. These metrics were selected in order to have detailed information about differences among precipitation products.

\subsubsection{Discharge data}

Daily river gauge data were obtained from the Oum er Rbia Hydraulic Agency (ABHOER). Gauge measurements from two gauges in the western region of the basin were used in this study: Ait Ouchene and Mechra Eddahk (Fig. 1). Table 1 summarizes some key hydrological data.

\subsubsection{Evapotranspiration data}

The GLEAM (Global Land Evaporation Amsterdam Model - http://www.gleam.eu/) evapotranspiration product version 3.0a (GLEAM_v3.0a), generated by VU Amsterdam in collaboration with Ghent University (Miralles et al., 2011a, b; Martens et al., 2016b), was used to calibrate PCRGLOBWB. The product consists of a global data set based on reanalysis net radiation and air temperature, satellite- and gauged-based precipitation, vegetation optical depth (VOD) and snow water equivalents spanning the 35 -year period 1980-2014. To generate the GLEAM evapotranspiration product, the GLEAM model separately estimates the different components of terrestrial evaporation, including transpiration, interception loss, bare-soil evaporation, snow sublimation and open-water evaporation. To this end, it consists of four modules: evaporation, stress, soil-water balance and rainfall interception (Martens et al., 2016a). GLEAM $\left(0.25^{\circ} \times 0.25^{\circ}\right)$ was interpolated with distance-weighted average remapping to a $0.08^{\circ} \times 0.08^{\circ}$ grid for the period 1980 2010. GLEAM actual evapotranspiration thus obtained was subsequently compared to simulated actual evapotranspiration by PCR-GLOBWB.

\subsubsection{Soil moisture data}

The ESA CCI surface soil moisture combined product version 2.2 (ESA CCI SM v02.2 CP) was generated as part of the European Space Agency (ESA) soil moisture Climate Change Initiative (CCI) project by the Vienna University of Technology (http://www.esa-soilmoisture-cci.org/). A data set for the 35-year period 1980-2014 of surface soil moisture was produced using C-band scatterometer data (ERS-1/2 AMI scatterometer, MetOp Advanced Scatterometer - ASCAT) and multi-frequency radiometer data (from the SMMR, SSM/I, TMI, AMSR-E, Windsat and AMSR2 instruments). Soil moisture retrieved using satellite active microwave data and satellite microwave radiometry were merged to make best use of soil moisture data from the different available satellites and sensors (Liu et al., 2011, 2012; Dorigo et al., 2015). ESA CCI surface soil moisture combined product represents approximately a top soil layer depth of $0.5-2 \mathrm{~cm}$. Similarly to GLEAM evapotranspiration, ESA CCI soil moisture product at an original spatial resolution of $0.25^{\circ} \times 0.25^{\circ}$ was interpolated with distance-weighted av- 
Table 1. Hydrological and geographical information of the analysed catchments at the Oum er Rbia basin.

\begin{tabular}{llrrrr}
\hline Station name & River & Upstream basin & \multicolumn{2}{c}{ Outlet location } & Elevation \\
\cline { 4 - 5 } & & area $\left(\mathrm{km}^{2}\right)$ & Longitude & Latitude & $(\mathrm{m})$ \\
\hline Ait Ouchene & El Abid & 2350 & $6^{\circ} 10^{\prime} 48^{\prime \prime} \mathrm{W}$ & $32^{\circ} 13^{\prime} 30^{\prime \prime} \mathrm{N}$ & 1070 \\
Mechra Eddahk & Oum er Rbia & 6555 & $6^{\circ} 31^{\prime} 12^{\prime \prime} \mathrm{W}$ & $32^{\circ} 26^{\prime} 6^{\prime \prime} \mathrm{N}$ & 406 \\
\hline
\end{tabular}

Table 2. Calibration scenarios.

\begin{tabular}{ll}
\hline $\begin{array}{l}\text { Scenario } \\
\text { identifier }\end{array}$ & Description \\
\hline S0 & Reference scenario \\
S1 & Calibration using in situ-observed discharge time series \\
S2 & Calibration using GLEAM actual evapotranspiration times series \\
S3 & Calibration using ESA CCI surface soil moisture time series \\
S4 & Step-wise calibration: using GLEAM actual evapotranspiration \\
& and ESA CCI surface soil moisture time series \\
\hline
\end{tabular}

erage remapping to $0.08^{\circ} \times 0.08^{\circ}$ grid for the period 1980 2010.

ESA CCI surface soil moisture observations were compared to simulated soil moisture of the first of the three vertical soil layers in PCR-GLOBWB (top $5 \mathrm{~cm}$ of soil). Due to differences in layer depth and/or data characteristics, systematic biases between modelled and observed soil moisture may exist (Reichle and Koster, 2004). To overcome this expected discrepancy and match the remotely sensed observations to the statistics of corresponding hydrological model simulations, mean-standard deviation $(\mu-\sigma)$ matching (Draper et al., 2009) was used. This technique was implemented to rescale simulated soil moisture against ESA CCI surface soil moisture time series to have the same mean and variance.

The adjusted simulated surface soil moisture values $\theta_{\text {sim }}^{\prime}$ were calculated as

$\theta_{\mathrm{sim}}^{\prime}=\frac{\sigma_{\theta_{\mathrm{obs}}}}{\sigma_{\theta_{\mathrm{sim}}}} \times\left(\theta_{\mathrm{sim}}-\overline{\theta_{\mathrm{sim}}}\right)+\overline{\theta_{\mathrm{obs}}}$

where $\theta_{\text {sim }}$ represents the simulated soil moisture values, $\theta_{\text {obs }}$ the ESA CCI soil moisture observations, $\sigma_{\theta_{\text {sim }}}$ and $\sigma_{\theta_{\mathrm{obs}}}$ are the standard deviations of the simulated and observed soil moisture values and $\overline{\theta_{\mathrm{obs}}}$ and $\overline{\theta_{\mathrm{obs}}}$ are the means of the simulated and observed soil moisture values.

When comparing the original and the rescaled soil moisture, it is observed that the mean-standard deviation technique effectively removes the biases between the simulated and observed soil moisture time series (see Fig. S1 of the Supplement).

\subsection{Calibration and validation strategy}

Alternative single objective calibration approaches based on discharge, actual evapotranspiration and surface soil moisture and a multi-objective calibration approach based on ac- tual evapotranspiration and surface soil moisture were intercompared. Five different calibration scenarios were carried out. Calibration scenario S0 represents the reference calibration scenario, which was not locally calibrated for the Oum er Rbia basin, but uses a priori model parameters derived from vegetation, soil properties and geological information at a global scale (latest model version of PCR-GLOBWB). Calibration scenario $\mathrm{S} 1$ aims to calibrate the hydrological model using in situ discharge observations, following the traditional calibration approach. Calibration scenarios S2 and S3 use GLEAM actual evapotranspiration and ESA CCI surface soil moisture time series for calibration, respectively. Calibration scenario $\mathrm{S} 4$ represents the multi-objective calibration approach and it consists of a step-wise calibration scheme that attempts to combine the strengths of calibration scenarios S2 and S3. The first step is simply scenario S2, where all the model parameters can be adjusted based on GLEAM actual evapotranspiration. In the second step, those parameters that are clearly identified by calibration scenario $\mathrm{S} 2$ are held constant and the remaining parameters can be adjusted according to ESA CCI surface soil moisture, calibration scenario S3.

The five calibration scenarios were analysed for each of the three global precipitation products to study their impact on model parameters calibration and model performance. The calibration scenarios are described in Table 2, including the scenario identifier.

For the calibration using in situ-observed discharge time series (S1), two river gauge observation time series were used (Sect. 3.2.2). The objective function to maximize for the calibration scenarios was KGE, instead of the traditional mean squared error (MSE) or NSE to avoid underestimating the variability of values (Gupta et al., 2009). The mathematical formulation and description of the used objective function are included in Sect. 3.4. 
To calibrate PCR-GLOBWB for each of the three precipitation products, 81 runs with different parameter values were simulated: minimum soil water capacity $\left(W_{\min }\right)$, soil saturated hydraulic conductivities $\left(K_{\text {sat } 1}, K_{\text {sat2 }}\right.$ and $\left.K_{\text {sat3 } 3}\right)$ and baseflow recession coefficient $(J)$. These model parameters, which vary spatially over the basin, influence different model parts of the model behaviour, as explained in Sect. 3.1. For the variation of the parameter values, spatially uniform prefactors were used: $f_{\mathrm{w}}, f_{K}$ and $f_{j}$ (Table 3 ). The remaining model parameters were kept fixed.

The pre-factors to vary model parameter values were referred to as the parameters of the $\mathrm{S} 0$ calibration scenario. The spatial distribution of the parameters $W_{\min }, K_{\text {sat }}$ and $J$ used in the S0 scenario can be found in Fig. A1 of Appendix A.

Furthermore, the uncertainty of reference potential evapotranspiration $\left(E_{\mathrm{p}, 0_{\text {ref }}}\right)$ was also investigated using a correction pre-factor, $f_{\mathrm{e}}$, to this model variable. Considered values for $f_{\mathrm{e}}$ pre-factor are included with the previously mentioned ones in Table 3.

As a reference calibration scenario, S0 pre-factors are: $f_{\mathrm{w}}=1, f_{K}=0, f_{j}=1$ and $f_{\mathrm{e}}=1$. The model performances of all the simulations were evaluated for each of the five calibration scenarios to identify the best pre-factor sets as the calibrated pre-factor sets.

All the simulations were performed at a daily temporal resolution for the 32-year period 1979-2010. The 2-year period 1979-1980 was used to spin up the hydrological model until reaching a dynamically steady state. The model was calibrated based on monthly values of discharge, actual evapotranspiration and surface soil moisture. Validation was also carried out at a monthly temporal resolution but exclusively for streamflow, aiming to analyse if similar discharge estimates may be obtained with a calibrated model based on remotely sensed observations (S2, S3 and S4), in comparison with a model traditionally calibrated to in situ discharge data (S1). The 13-year period 1981-1993 was used for model calibration, and during the 17-year period 1994-2010, the model was validated.

\subsection{Performance metrics}

To inter-compare the three global precipitation products, six metrics were used: NSE, KGE, $r$ and PBias. Moreover, one of those metrics, KGE, was chosen as an objective function to calibrate and validate model performance for each calibration scenario. NSE, PBias and $r$ were also used as additional assessment measurements in the validation procedure.

Nash-Sutcliffe efficiency (Nash and Sutcliffe, 1970), NSE, is defined as

$\mathrm{NSE}=1-\frac{\sum_{t=1}^{n}[x(t)-y(t)]^{2}}{\sum_{t=1}^{n}[y(t)-\bar{y}]^{2}}$,

where $x(t)$ and $y(t)$ are the modelled and observed variable at $t$ time step (months), $\bar{y}$ is the mean of observed data and $n$ is the total number of observations. NSE is widely used for calibrating and validating hydrological models in terms of discharge. NSE varies from $-\infty$ to 1 . If NSE $=0$, modelled values perform as well as the mean of the observations. If NSE $<0$, modelled values perform worse than the mean of the observations.

Gupta et al. (2009) analysed various decompositions of NSE and proposed an alternative model performance criteria, KGE, to avoid the problems that can be derived from using the NSE criterion (e.g. high sensitivity to extreme values and bias). KGE is given as

$\mathrm{KGE}=1-\sqrt{(r-1)^{2}+(\alpha-1)^{2}+(\beta-1)^{2}}$,

where $r$ represents Pearson's correlation coefficient, $\alpha$ is the ratio between the variance of the modelled variable and the variance of the observed variable and $\beta$ is the ratio between the mean of the modelled variable and the mean of the observed variable, i.e. $\beta$ represents the bias. Analogous to NSE, KGE ranges from $-\infty$ to 1 with an ideal value of 1 . KGE measures simultaneously bias, variability and correlation.

Pearson's correlation coefficient (Pearson, 1896) measures the degree of linear association between modelled and observed values and it is defined as

$r=\frac{\sum_{t=1}^{n}(x(t)-\bar{x})(y(t)-\bar{y})}{\sqrt{\sum_{t=1}^{n}(x(t)-\bar{x})^{2}} \sqrt{\sum_{t=1}^{n}(y(t)-\bar{y})^{2}}}$,

where $x(t)$ and $y(t)$ are the modelled and observed variable at $t$ time step (months), $\bar{y}$ is the mean of observed data, $\bar{x}$ is the mean of modelled data and $n$ is the total number of observations. Pearson's correlation coefficient, $r$, varies within the interval $[-1,1]$. This coefficient is mainly used in hydrological modelling to evaluate the timing of modelled to observed time series.

Percent bias indicates the average tendency of the modelled values to over- or underestimate the observations, and it is calculated in percentage terms as

PBias $=100 \times \frac{\sum_{t=1}^{n}(x(t)-y(t))}{\sum_{t=1}^{n} y(t)}$.

The optimal value of PBias is 0 .

When the performance metrics were calculated between simulated and observed soil moisture estimates, the subscript ${ }_{\mathrm{sm}}$ was added to the metric, i.e. $\mathrm{NSE}_{\mathrm{sm}}, \mathrm{KGE}_{\mathrm{sm}}, r_{\mathrm{sm}}$ and PBias ${ }_{\mathrm{sm}}$. Similarly, when comparing actual evapotranspiration estimates, precipitation and discharge, the added subscripts were evap, precip and $q$, respectively.

\section{Results}

\subsection{Inter-comparison of precipitation products}

To inter-compare the precipitation products, the annual mean precipitation for the study time period (1979-2010) for each 
Table 3. Parameter values used in the calibration processes.

\begin{tabular}{llll}
\hline $\begin{array}{l}\text { Parameters } \\
\text { ID }\end{array}$ & Description & Pre-factors & Parameter values \\
\hline$W_{\text {min }}$ & Minimum soil water capacity & $f_{\mathrm{w}} \in\{0.75,1,1.25\}$ & $W_{\min }=f_{\mathrm{w}} \cdot W_{\max }$ \\
$K_{\text {sat } 1}$ & Saturated hydraulic conductivity of first soil layer & $f_{k} \in\{-0.25,0,0.25\}$ & $\log \left(K_{\mathrm{sat} 1}\right)=f_{k}+\log \left(K_{\left.\mathrm{sat} 1_{\mathrm{ref}}\right)}\right)$ \\
$K_{\mathrm{sat} 2}$ & Saturated hydraulic conductivity of second soil layer & $f_{k} \in\{-0.25,0,0.25\}$ & $\log \left(K_{\mathrm{sat} 2}\right)=f_{k}+\log \left(K_{\mathrm{sat} 2}\right)$ \\
$K_{\mathrm{sat} 3}$ & Saturated hydraulic conductivity of third soil layer & $f_{k} \in\{-0.25,0,0.25\}$ & $\log \left(K_{\mathrm{sat} 3}\right)=f_{k}+\log \left(K_{\mathrm{sat} 3 \mathrm{ref}}\right)$ \\
$J$ & Baseflow recession coefficient & $f_{j} \in\{-0.5,0,0.5\}$ & $\log (J)=f_{j}+\log \left(J_{\mathrm{ref}}\right)$ \\
$E_{\mathrm{p}, 0}$ & Reference potential evapotranspiration & $f_{\mathrm{e}} \in\{0.75,1,1.25\}$ & $E_{\mathrm{p}, 0}=f_{\mathrm{e}} \cdot E_{\mathrm{p}, 0_{\mathrm{ref}}}$ \\
\hline
\end{tabular}

(a)
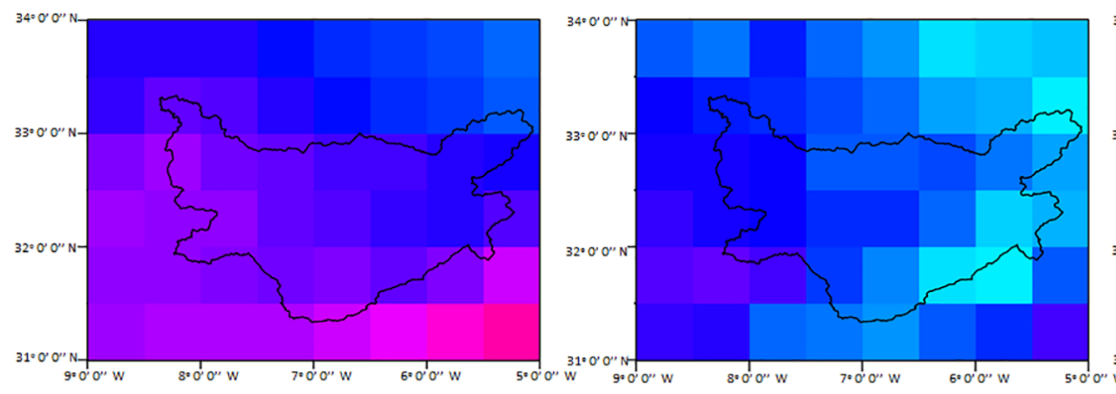

(d)

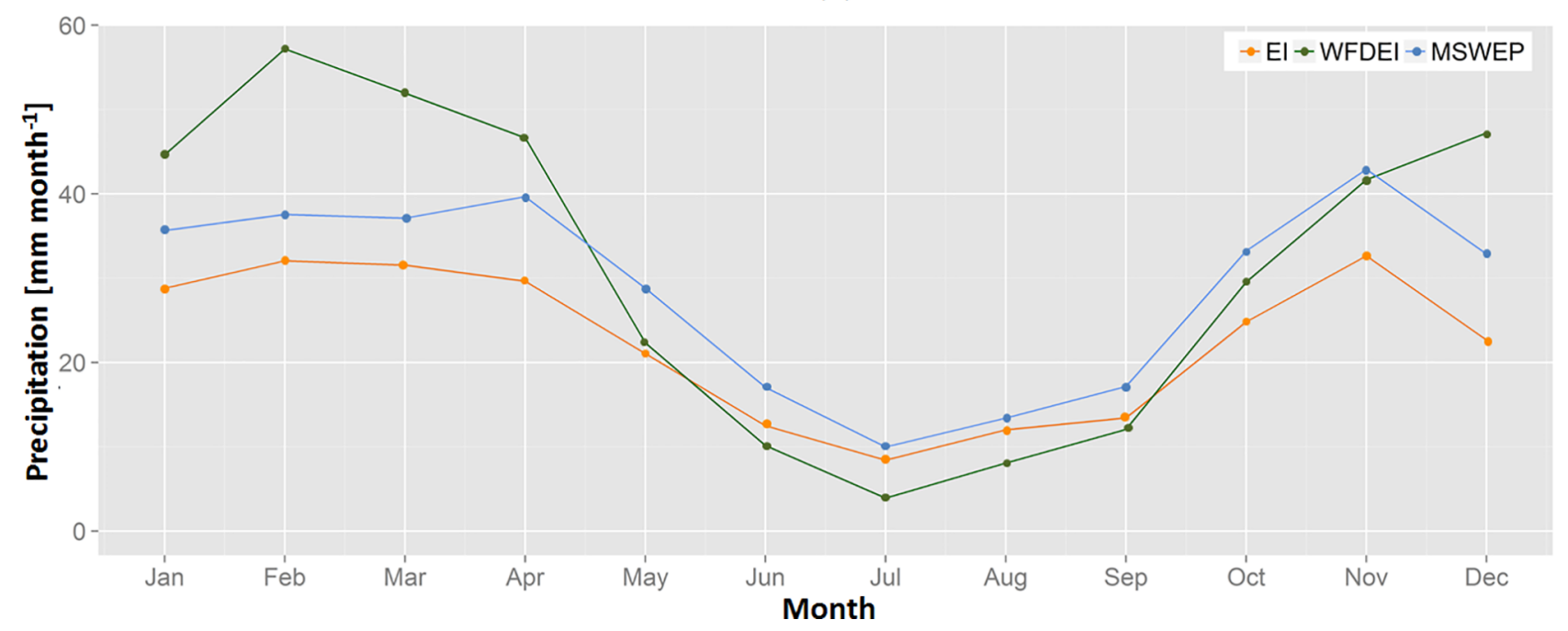

Figure 3. (a) EI annual mean precipitation, (b) WFDEI annual mean precipitation and (c) MSWEP annual mean precipitation for 1979-2010 time period and (d) climatology of EI, WFDEI and MSWEP precipitation products.

forcing data set was calculated (Fig. 3a, b and c). In addition to the spatial resolution difference, MSWEP was able to capture the rainfall pattern over the Atlas Mountains rather well, which was only roughly distinguished by WFDEI and unrecognized by EI. The finer spatial resolution and the combination of reanalysis, satellite and in situ data are probably the reasons for its more plausible spatial pattern. Furthermore, climatology of precipitation products was analysed (Fig. 3d). WFDEI ranged from $4.5 \mathrm{~mm}$ in July to $57 \mathrm{~mm}$ in February, whereas EI and MSWEP showed a lesser variability with precipitation values from $10.5 \mathrm{~mm}$ in July to $42.6 \mathrm{~mm}$ in November. Smaller differences between WFDEI and EI and MSWEP were observed during the summer months. EI and MSWEP showed similar temporal precipitation patterns. Annual mean precipitation over the entire basin obtained with MSWEP (355.15 mm) was approximately $80 \mathrm{~mm}$ higher than with EI (276.67 mm). Similar annual median values were obtained with the three global precipitation products, although the distribution of WFDEI highly differed from the other two products. 


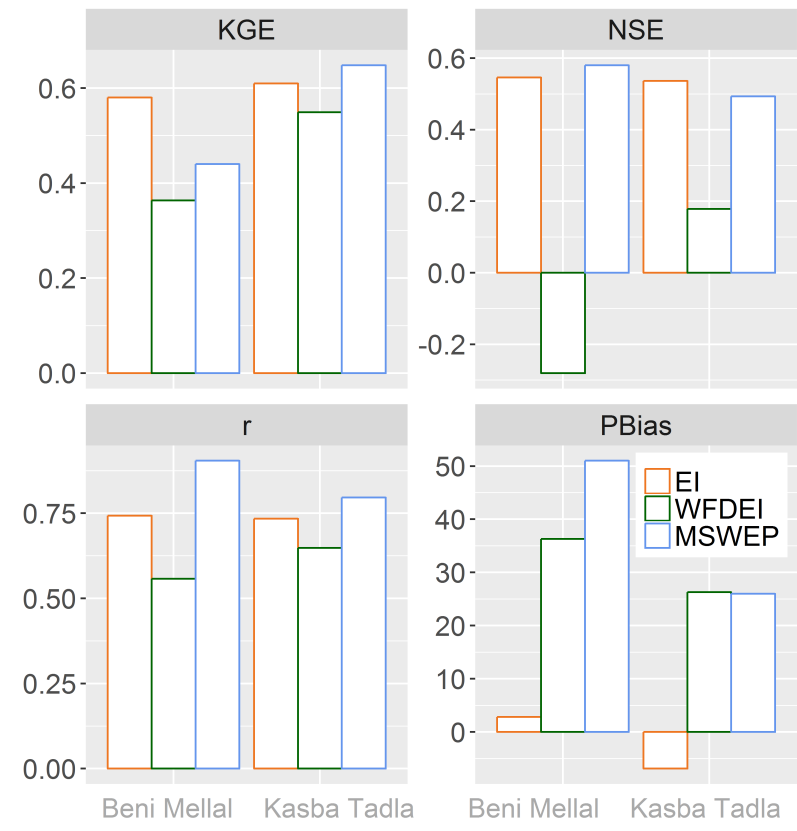

Figure 4. Performance metrics of daily EI, WFDEI and MSWEP precipitation products at Beni Mellal and Kasba Tadla weather stations, including KGE, NSE, $r$ and PBias.

Moreover, various performance metrics between the interpolated and in situ ground data were calculated and shown in Fig. 4. Overall, EI and MSWEP provided a better fit to the station data compared to WFDEI, with higher $\mathrm{KGE}_{\text {precip }}$, $\mathrm{NSE}_{\text {precip }}$ and $r_{\text {precip }}$ than WFDEI. When comparing EI with MSWEP, similar values of $\mathrm{KGE}_{\text {precip }}$ and $\mathrm{NSE}_{\text {precip }}$ were found, whereas higher differences existed in $r_{\text {precip }}$ and

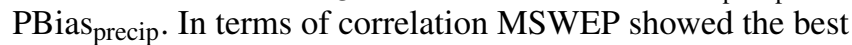
performance, but EI showed the lowest PBias at both weather stations, with a value of less than $10 \%$. Only two weather stations were found within the basin for the previous analysis. These measurements were considered too scarce to cover the basin and to discard the precipitation product with the worst performance (WFDEI). Therefore, the three global precipitation products were used to calibrate PCR-GLOBWB under the five calibration scenarios.

\subsection{Calibration results}

Model parameters were calibrated using discharge, evapotranspiration and soil moisture observations through five different calibration scenarios for the time period 1981-1993. Figure 5 shows results of all runs produced in this study for different calibration scenarios based on in situ discharge observations (S1) at Ait Ouchene (Fig. 5a) and Mechra Eddahk (Fig. 5b), GLEAM actual evapotranspiration (S2, Fig. 5c) and ESA CCI surface soil moisture (S3, Fig. 5d). For each panel in Fig. 5, KGE results ( $y$ axis) of using the three precipitation products were plotted in different rows (top, EI; mid- dle, WFDEI; bottom, MSWEP) and pre-factor values were plotted in different columns ( $x$ axis: first column, $f_{\mathrm{e}}$; second column, $f_{j}$; third column, $f_{k}$; fourth column, $f_{\mathrm{w}}$ ). Each scatter plot contains 81 dots representing each run with a different combination of parameter values. This means that the KGE values are the same in the four scatter plots of a row ( $y$ axis), but in each of these scatter plots, they were plotted against a different pre-factor ( $x$ axis). With Fig. 5, pre-factor ranges (and therefore parameter ranges) leading to better and worse performances could be distinguished, as well as their global optimal values. If no optimal value could be inferred, pre-factors from the calibration scenario $\mathrm{S} 0$ were maintained $\left(f_{\mathrm{e}}=1, f_{j}=0, f_{k}=0\right.$ and $\left.f_{\mathrm{w}}=1\right)$.

Once the best runs for each calibration scenario were identified, their discharge performance was checked at the two gauging stations: Mechra Eddahk, in Fig. 6, and Ait Ouchene, in Fig. S2. Observed discharge ( $y$ axis) and estimated discharge ( $x$ axis) were plotted in Fig. 6 for the five calibration scenarios. Different rows in Fig. 6 indicate the three global precipitation products (top, EI; middle, WFDEI; bottom, MSWEP) and different columns indicate the five calibration scenarios (first column, S0; second column, S1; third column, S2; fourth column, S3; fifth column, S4). The performance indicators NSE and KGE for discharge were included in every scatter plot in Fig. $6\left(\mathrm{NSE}_{q}\right.$ and $\left.\mathrm{KGE}_{q}\right)$.

To summarize results shown in Figs. 5 and 6, Table 4 includes for each calibration scenario the identified optimal parameters values and the $\mathrm{KGE}_{q}$ performance values at Ait Ouchene and Mechra Eddahk.

\subsubsection{Calibration using in situ-observed discharge time series (S1)}

Figure $5 \mathrm{a}$ and $\mathrm{b}$ (calibration scenario $\mathrm{S} 1$ ) are similar. From these panels, $f_{\mathrm{e}}$ (first column) and $f_{\mathrm{w}}$ (fourth column) were well identified by discharge calibration at both gauging stations when forced with any of the three precipitation products. Pre-factors of $f_{\mathrm{e}}=1.25$ and $f_{\mathrm{w}}=1.25$ led to the highest $\mathrm{KGE}_{q}$ values. However, it was not possible to identify the best pre-factors of $f_{j}$ (second column) and $f_{k}$ (third col$u m n$ ). There were no clear or distinct maximum values in the scatter plots of these panels; hence $f_{j}=0$ and $f_{k}=0$ were used.

From Fig. 6 (second column), the highest discharge performance was obtained when the model was calibrated with in situ discharge observations (S1).

For all the calibration scenarios, a few general observations could be made. Scatter plots (Fig. 6) highlighted an overall better agreement and a lower bias between discharge observations and estimates for the Ait Ouchene (see Fig. S2) than for Mechra Eddahk station. $\mathrm{KGE}_{q}$ values at Ait Ouchene station for calibration scenario S0 were lower than for Mechra Eddahk station. This may be due to their different locations within the basin, the former being situated in the Atlas Mountains, where precipitation estimates can be 
Table 4. Parameter identifiability values and optimal values for each calibration scenario.

\begin{tabular}{lllllrr}
\hline $\begin{array}{l}\text { Calibration } \\
\text { scenario }\end{array}$ & $f_{\mathrm{e}}$ & $f_{j}$ & $f_{k}$ & $f_{\mathrm{w}}$ & KGE (Ait Ouchene) & KGE (Mechra Eddahk) \\
\hline S0 & 1 & 0 & 0 & 1 & $0.470 /-1.906 /-0.542^{2}$ & $0.607 / 0.325 / 0.561$ \\
S1 & 1.25 & NI & NI & 1.25 & $0.510 /-0.494 / 0.520$ & $0.688 / 0.439 / 0.703$ \\
S2 & 1.25 & NI & NI & NI & $0.508 /-0.580 / 0.342$ & $0.602 / 0.423 / 0.693$ \\
S3 & NI & NI & 0.25 & 1.25 & $0.487 /-0.607 / 0.331$ & $0.634 / 0.369 / 0.613$ \\
S4 & 1.25 & NI & 0.25 & 1.25 & $0.478 /-0.768 / 0.271$ & $0.522 / 0.328 / 0.573$ \\
\hline
\end{tabular}

${ }^{1} \mathrm{NI}$ indicates that the parameter was not identifiable. ${ }^{2}$ KGE values are obtained from observed and simulated discharge when PCR-GLOBWB is forced with EI/WFDEI/MSWEP.

(a)

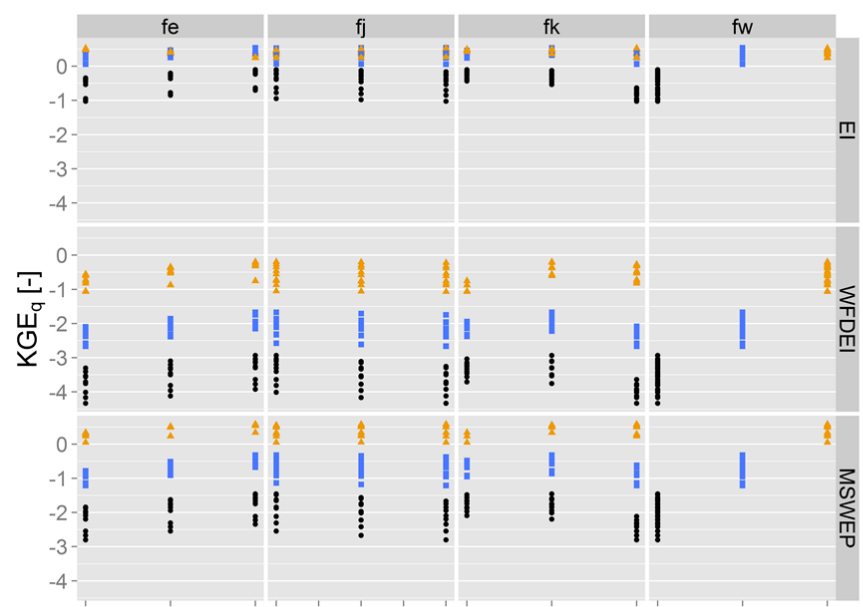

(c)

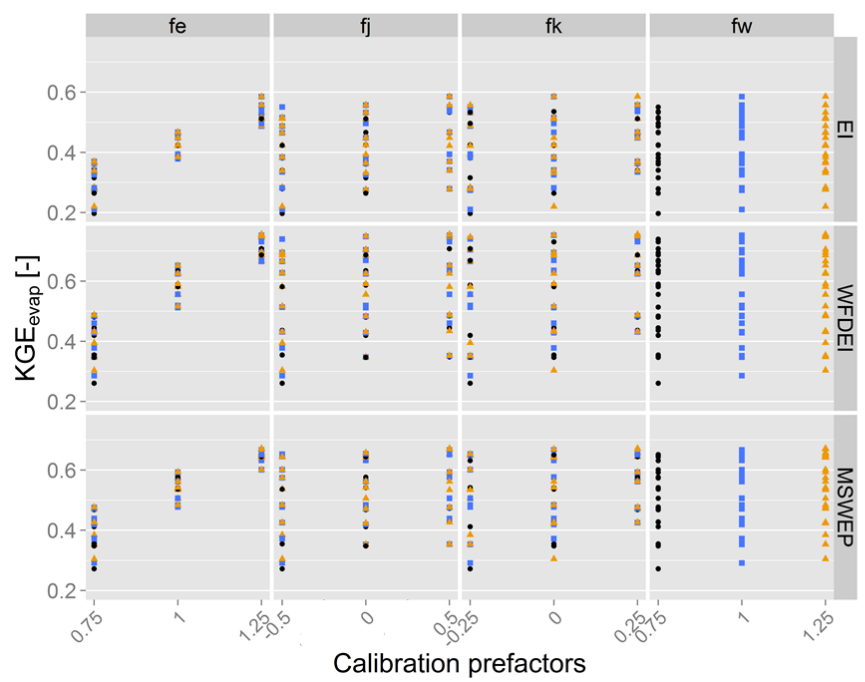

(b)

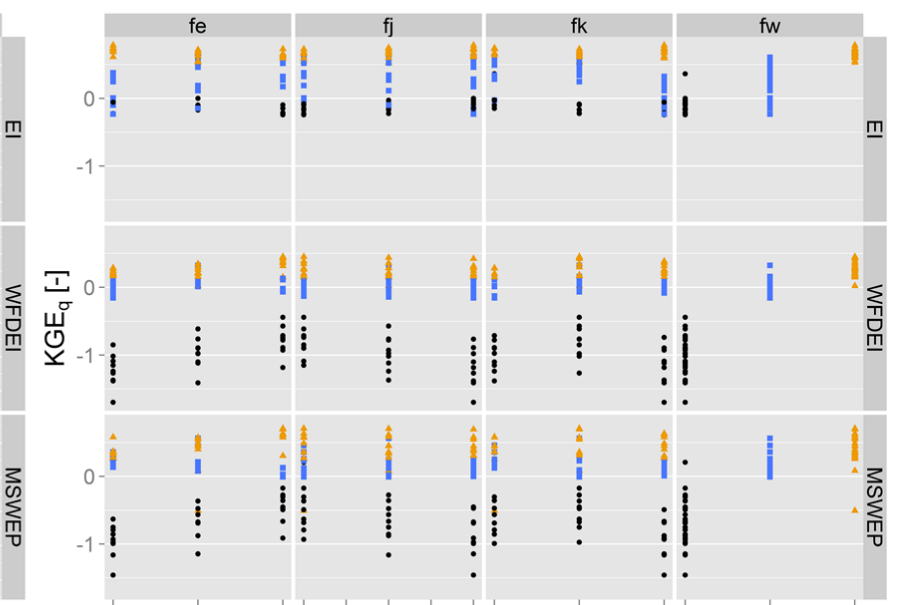

(d)

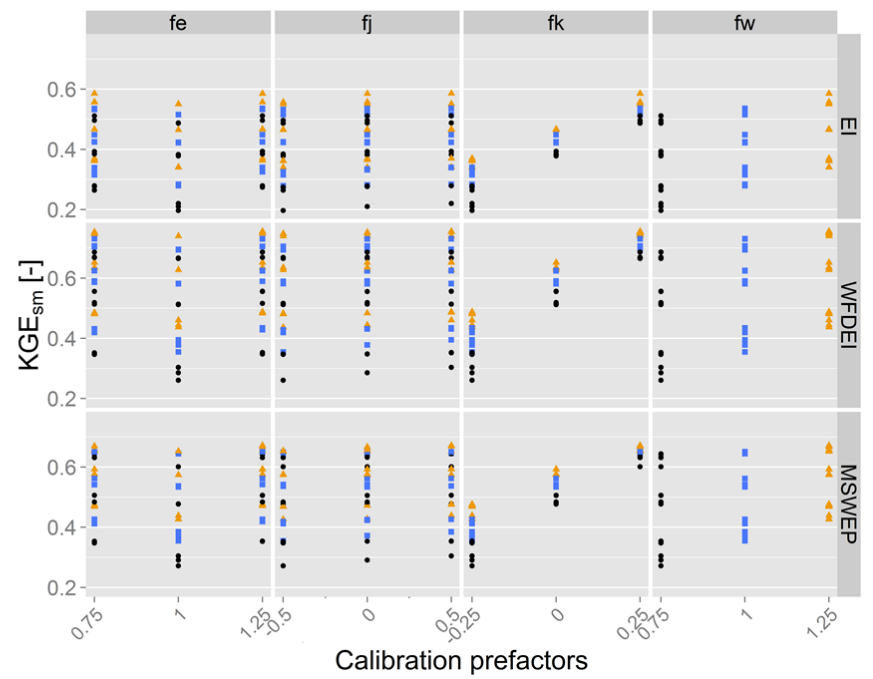

Figure 5. Scatter plots of discharge performance indicator KGE based on the monthly observations versus pre-factors $f_{\mathrm{e}}, f_{j}, f_{k}$ and $f_{\mathrm{w}}$ for the calibration scenarios S1 ((a) Ait Ouchene (b) Mechra Eddahk), S2 (c) and S3 (d). In each panel, columns indicate the different calibrated pre-factors and rows indicate the three global precipitation products used as model forcing. Different colours and dot shapes indicate different $f_{\mathrm{W}}$ values. 


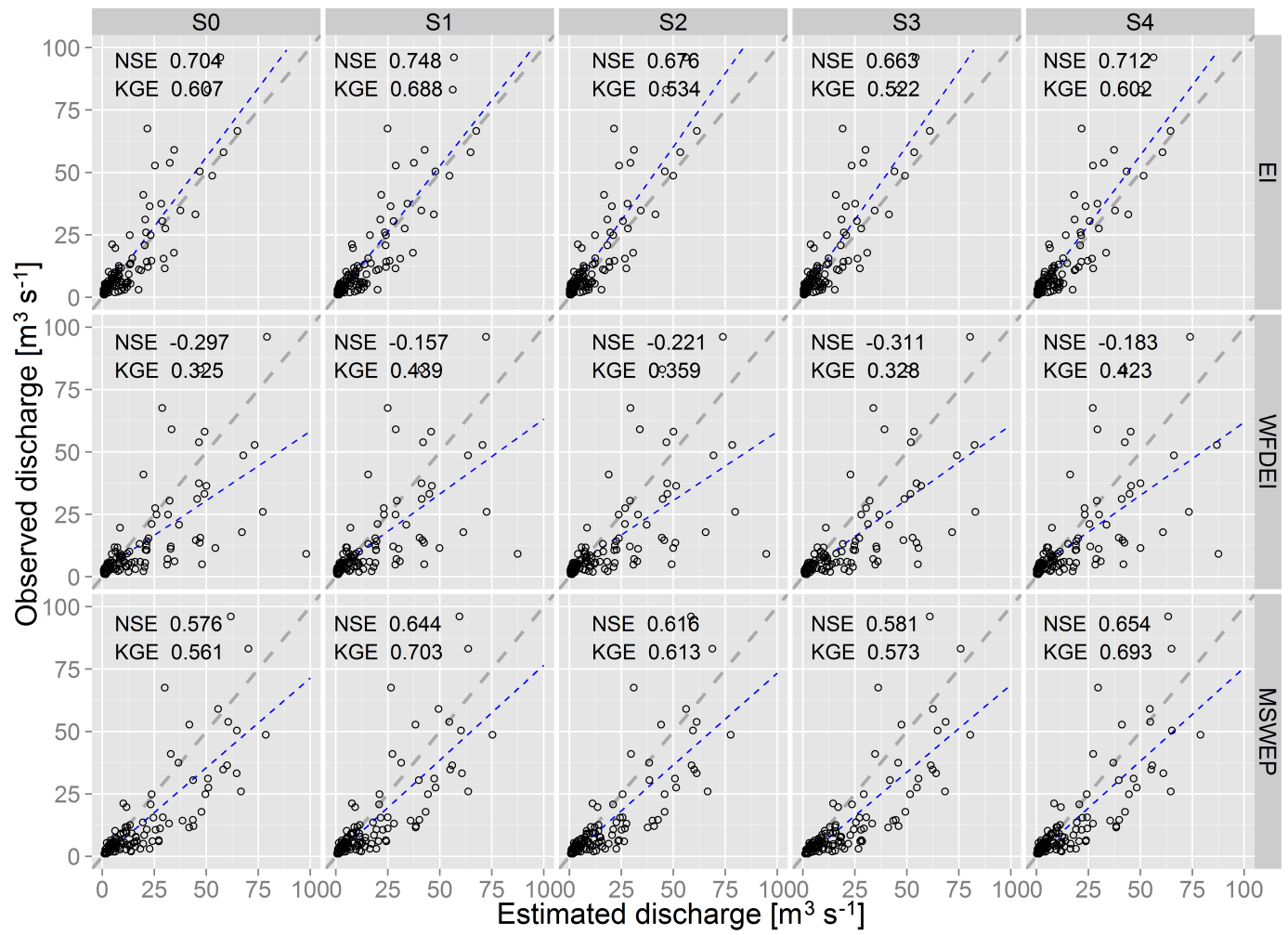

Figure 6. Scatter plots of monthly estimated discharge ( $x$ axis) and observed discharge ( $y$ axis) at Mechra Eddahk. Rows indicate the three global precipitation products and columns indicate the five calibration scenarios.

less accurate, and in a tributary of the Oum er Rbia River, whose representation in PCR-GLOBWB can be limited by the model spatial resolution.

Scatter plots (Fig. 6) also showed that estimated discharges were closer to observed discharges at both gauging stations when PCR-GLOBWB was forced with EI precipitation. Moreover, scatter plots indicated a worse agreement and a tendency to overestimate discharge when WFDEI and MSWEP were used. $\mathrm{KGE}_{q}$ values for the reference calibration scenario S0 at Mechra Eddahk were 0.607, 0.325 and 0.561 when EI, WFDEI and MSWEP were used as forcing data, respectively. These performance discrepancies were related to the differences between EI, WFDEI and MSWEP precipitation products discussed in Sect. 4.1. The lower quality of WFDEI in this region compared with the other precipitation data sets may be a possible reason for the lower discharge performance. When MSWEP was compared with in situ precipitation data, performance in terms of correlation was higher than EI. However, EI showed less bias. The higher performance of discharge estimates when PCR-GLOBWB was forced with EI may be due to this bias difference and that the validation was carried out at a monthly temporal resolution, reducing the impact of correlation.

\subsubsection{Calibration using GLEAM actual evapotranspiration time series (S2)}

Figure 5c (calibration scenario S2) indicated that only prefactor $f_{\mathrm{e}}$ (first column) could be clearly identified (the highest $\mathrm{KGE}_{\text {evap }}$ values were obtained with $f_{\mathrm{e}}=1.25$ ), whereas the remainder of the pre-factors $\left(f_{j}, f_{\mathrm{w}}\right.$ and $\left.f_{k}\right)$ were non identifiable, suggesting that evapotranspiration-based calibration may be unreliable in their identification. Therefore, the model run with pre-factors $f_{\mathrm{e}}=1.25, f_{j}=0, f_{k}=0$ and $f_{\mathrm{w}}=1$ was considered as the calibrated run based on the evapotranspiration performance.

From Fig. 6 (third column), results indicated an increase of $\mathrm{KGE}_{q}$ and $\mathrm{NSE}_{q}$ values when GLEAM evapotranspiration was used for model calibration compared to the reference scenario (S0, first column of Fig. 6). However, higher model performance values were obtained when calibrating based on in situ discharge observations (S1, second column of Fig. 6).

\subsubsection{Calibration using ESA CCI surface soil moisture time series (S3)}

Figure 5d (calibration scenario S3) indicated that pre-factors $f_{k}$ (third column) and $f_{\mathrm{w}}$ (fourth column) could be identified, $f_{\mathrm{w}}=1.25$ and $f_{k}=0.25$. There was a clear maximum value of $\mathrm{KGE}_{\mathrm{sm}}$ with these pre-factors values. Pre-factors $f_{\mathrm{e}}$ 
(first column) and $f_{j}$ (second column) were not identifiable when soil moisture was used for calibration. Therefore, the calibrated run based on soil moisture performance was the model run with pre-factors $f_{\mathrm{e}}=1, f_{j}=0, f_{k}=0.25$ and $f_{\mathrm{w}}=1.25$. This implies that ESA CCI soil moisture may be used to indirectly tune groundwater recharge by calibrating the upper soil saturated hydraulic conductivities, $K_{\text {sat }}$.

From Fig. 6 (fourth column), scatter plots indicated an improvement in the correspondence between observed and estimated discharge compared to the non-calibrated scenario (S0, first column of Fig. 6). Similarly to calibration scenario S2 (third column of Fig. 6), this improvement was lower than when the model was calibrated based on ground discharge observations (S1, second column of Fig. 6).

The calibrated runs based on evapotranspiration (S2, third column of Fig. 6) and soil moisture (S3, fourth column of Fig. 6) resulted in lower discharge performances compared to the reference scenario (S0) in some cases (e.g. when EI precipitation was used at Mechra Eddahk location: $\mathrm{KGE}_{q}(\mathrm{~S} 0)=$ $0.607, \mathrm{KGE}_{q}(\mathrm{~S} 2)=0.534$ and $\mathrm{KGE}_{q}(\mathrm{~S} 3)=0.522$. $)$

\subsubsection{Step-wise calibration using GLEAM actual evapotranspiration and ESA CCI surface soil moisture time series (S4)}

Calibration scenario S4 attempted to combine the strengths of scenarios S2 and S3. In the first step, the model was calibrated using GLEAM evapotranspiration (S2, Fig. 5c). From Fig. 5c, only $f_{\mathrm{e}}$ pre-factor was well identified (the highest $\mathrm{KGE}_{\text {evap }}$ value was obtained with $f_{\mathrm{e}}=1.25$ ). In the second step, $f_{\mathrm{e}}$ pre-factor that had been identified was held constant and the remaining three pre-factors were allowed to be calibrated according to ESA CCI soil moisture (S3, Fig. 5d). From Fig. 5d, $f_{\mathrm{w}}$ and $f_{k}$ were identifiable (the highest $\mathrm{KGE}_{\mathrm{sm}}$ values were obtained with $f_{\mathrm{w}}=1.25$ and $f_{k}=0.25$ ). As a result, for calibration scenario S4, the prefactors identified were $f_{\mathrm{e}}=1.25$ during the evapotranspiration calibration (S2) and $f_{\mathrm{w}}=1.25$ and $f_{k}=0.25$ during the soil moisture calibration (S3). This step-wise calibration approach using multiple system variables allowed us to identify more parameters than when those variables were separately used. Nonetheless, neither of the steps in calibration scenario S4 allowed the clear identification of $f_{j}$, so its value for the calibration scenario S0 was used, $f_{j}=0$.

From Fig. 6 (fifth column), calibration using GLEAM evapotranspiration and ESA CCI soil moisture led to further improvements than when these observations were separately used. For example, when MSWEP precipitation was used to model discharge at Mechra Eddahk station, $\mathrm{KGE}_{q}$ varied among $0.703,0.693,0.613$ and 0.573 for calibration scenarios S1, S4, S2 and S3, respectively $\left(\mathrm{KGE}_{q}=0.561\right.$ for the reference scenario S0). At Ait Ouchene station (see Fig. S2), $\mathrm{KGE}_{q}$ varied among $0.520,0.342,0.331$ and 0.271 for calibration scenarios S1, S4, S2 and S3, respectively $\left(\mathrm{KGE}_{q}=-0.542\right.$ for the reference scenario $\left.\mathrm{S} 0\right)$.

\subsection{Validation results}

Once the model had been calibrated for each calibration scenario and each precipitation product, comparisons between estimates (before and after the calibration) and observations of actual evapotranspiration, surface soil moisture and discharge were carried out for the validation time period (19942011). To perform the analysis of these results, time series plots were included in Figs. 7 and 8.

In Fig. 7a, simulated actual evapotranspiration time series of the reference run ( $\mathrm{S} 0$, red dashed line) and the step-wise calibrated run (S4, purple dashed line) were plotted against GLEAM actual evapotranspiration observations (black line). Similarly, in Fig. 7b shows simulated surface soil moisture of the reference run (S0, red dashed line) and the stepwise calibrated run (S4, purple dashed line) plotted against ESA CCI surface soil moisture time series (black line). The rescaled soil moisture time series (after mean-standard deviation matching technique applied; see Sect. 3.2.4) are shown. In Fig. 7c, estimated discharge of the reference run (S0, red dashed line) and the step-wise calibrated run (S4, purple dashed line) were plotted against discharge observations (black line) at Mechra Eddahk. KGE values for actual evapotranspiration, surface soil moisture and discharge were included in Fig. 7a, b and c. For the sake of simplicity, only results from when the model was forced with MSWEP precipitation are shown.

Similarly to Fig. 7, Fig. 8 shows simulated evapotranspiration (Fig. 8a), surface soil moisture (Fig. 8b) and discharge (Fig. 8c) against observations. However, in Fig. 8, estimates of the discharge-calibrated run (S1, red dashed line) and the step-wise calibrated run (S4, purple dashed line) were plotted against observations (black line). With Fig. 8, the impact on calibration of using in situ discharge and remotely sensed evapotranspiration and soil moisture observations could be compared.

Reference run (S0) provided evapotranspiration (Fig. 7a) and soil moisture (Fig. 7b) estimates fairly close to observations with $\mathrm{KGE}_{\text {evap }}=0.586$ and $\mathrm{KGE}_{\mathrm{sm}}=0.828$. Discharge estimates of calibration scenario S0 performed well at Mechra Eddahk (Fig. 7c). Discharge performance of the reference run (S0) was lower at Ait Ouchene. From Fig. 7a, the calibration procedure based on GLEAM evapotranspiration and ESA CCI soil moisture (S4) produced an increase of $18 \%$ in $\mathrm{KGE}_{\text {evap }}$ compared to the reference run (S0). From Fig. 7b, estimated and observed surface soil moisture time series showed good correspondence. $\mathrm{KGE}_{\mathrm{sm}}$ difference of 0.028 was found between the reference (S0) and the stepwise (S4) calibration scenarios. From Fig. 7c, the step-wise calibrated run (S4) reproduced the monthly observed discharge well, except some simulated extreme peaks which were not observed, e.g. January and June in 2002 and some which were not simulated properly, e.g. January and May in 1996 and 1997. This lack of fit may be due to errors in the precipitation data, because higher discharge differences 
(a)

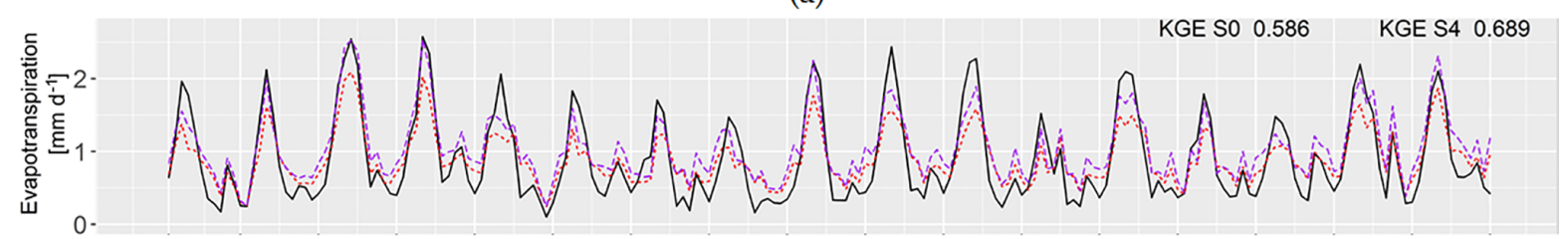

(b)

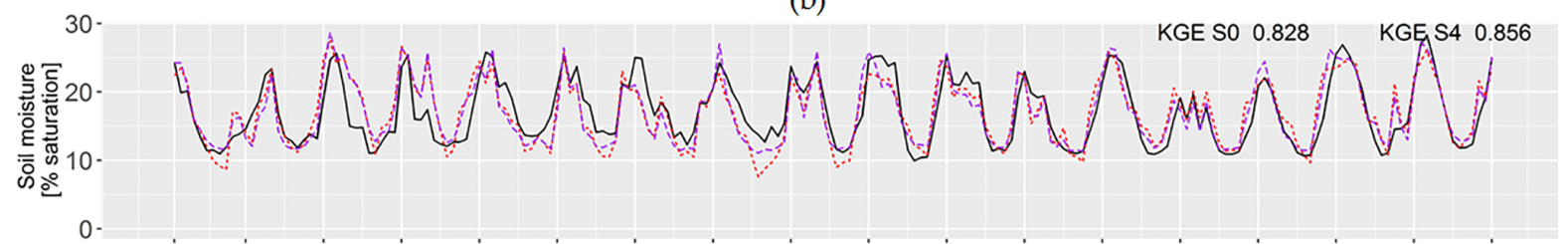

(c)

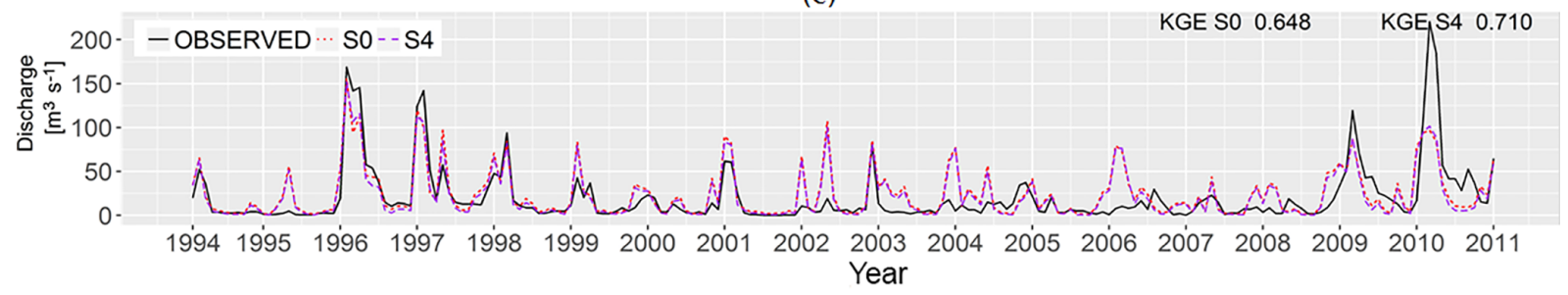

Figure 7. (a) Monthly GLEAM actual evapotranspiration (black) and estimated actual evapotranspiration (red and purple) time series over the entire Oum er Rbia basin. (b) Monthly ESA CCI soil moisture (black) and estimated soil moisture (red and purple) time series over the entire Oum er Rbia basin. (c) Monthly observed discharge (black) and estimated discharge (red and purple) time series at Mechra Eddahk. The red dashed lines represent estimates from calibration scenario S0 (reference scenario). The purple dashed lines represent the calibrated time series from calibration scenario S4 which are taken from the runs that yield the best simulations. Estimated time series over the entire Oum er Rbia basin for the validation time period obtained with MSWEP precipitation are shown.

were shown when WFDEI and MSWEP products were used in comparison to the EI product. Other possible reasons may be related to model structural deficiencies. When comparing discharge time series (Fig. 7c), calibration scenario S4 slightly improved $\mathrm{KGE}_{q}$ compared to calibration scenario S0, with $\mathrm{KGE}_{q}$ values varying from 0.648 to 0.710 .

From Fig. $8 \mathrm{a}$, an increase of $14 \%$ in $\mathrm{KGE}_{\text {evap }}$ was produced when the discharge calibration scenario (S1) was used compared to the reference run (S0). This improvement in evapotranspiration estimates was higher when calibrating the model using GLEAM evapotranspiration and ESA CCI soil moisture $\left(\mathrm{S} 4, \mathrm{KGE}_{\text {evap }}=0.689\right)$ than when calibrating it only for ground discharge $\left(\mathrm{S} 1, \mathrm{KGE}_{\text {evap }}=\right.$ 0.666). Similarly to Fig. 8a showing the evapotranspiration comparison, Fig. $8 \mathrm{~b}$ indicated that a higher $\mathrm{KGE}_{\mathrm{sm}}$ value was obtained when using GLEAM and ESA CCI observations for calibration $\left(\mathrm{S} 4, \mathrm{KGE}_{\mathrm{sm}}=0.856\right)$ than when calibration was based on in situ discharge observations ( $\mathrm{S}$ 1, $\mathrm{KGE}_{\mathrm{sm}}=0.834$ ). From Fig. 8c comparing discharge time series at Mechra Eddahk, step-wise calibration scenario S4 led to an increase of $10 \%$ in $\mathrm{KGE}_{q}$, compared to the increase of $5 \%$ obtained when discharge observations were used for calibration (S1). However, at Ait Ouchene the discharge performance improvement was lower when evapotranspiration and soil moisture observations (S4) were used for calibration than when in situ discharge measurements were used (S1).
This may be due to the lower performance of the reference run (S0) at Ait Ouchene.

To further understand the added value of using GLEAM evapotranspiration and ESA CCI soil moisture data for model calibration and inter-compare the impact of the calibration scenarios, the variations of $\mathrm{KGE}_{q}, \mathrm{NSE}_{q}, r_{q}$ and $\mathrm{PBias}_{q}$ between each calibration scenario (S1, S2, S3 and S4) and the reference calibration scenario (S0) were calculated and plotted for the validation time period in Fig. 9. Rows indicate the three global precipitation products and columns indicate the performance indicators. The variations of the performance metrics are shown with bar plots for the two gauging stations, Ait Ouchene and Mechra Eddahk. At each location, a positive value of $\mathrm{KGE}_{q}, \mathrm{NSE}_{q}, \mathrm{PBias}_{q}$ and $r_{q}$ means that either $\mathrm{S} 1, \mathrm{~S} 2, \mathrm{~S} 3$ or $\mathrm{S} 4$ scenario obtained a higher skill score than $\mathrm{S} 0$, whereas a negative value means that those scores decreased after calibration.

Figure 9 showed that variations of the performance indicators were lower when EI precipitation product was used. The highest differences among the calibration scenarios were obtained when the model was forced with WFDEI precipitation. In the inter-comparison of the calibration scenarios, the calibration scenario using in situ-observed discharge data (S1) obtained overall the highest increase of $\mathrm{KGE}_{q}, \mathrm{NSE}_{q}$ and $r_{q}$ and the highest reduction of $\mathrm{PBias}_{q}$ when any of the precipitation products were used, as expected. Similar 
(a)

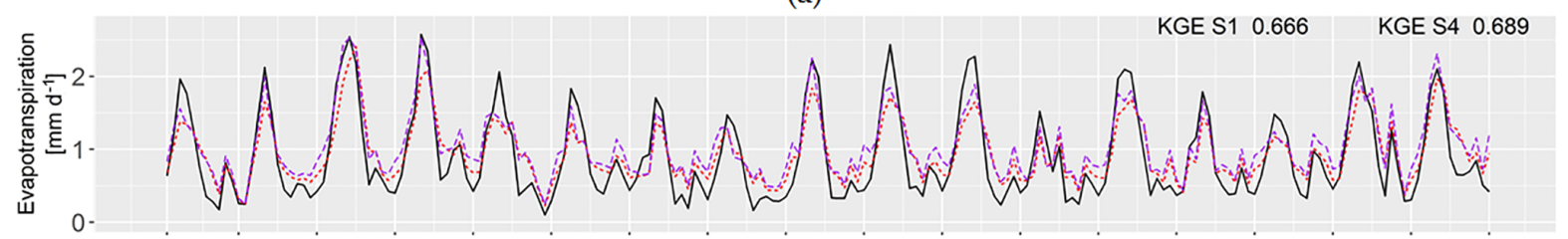

(b)

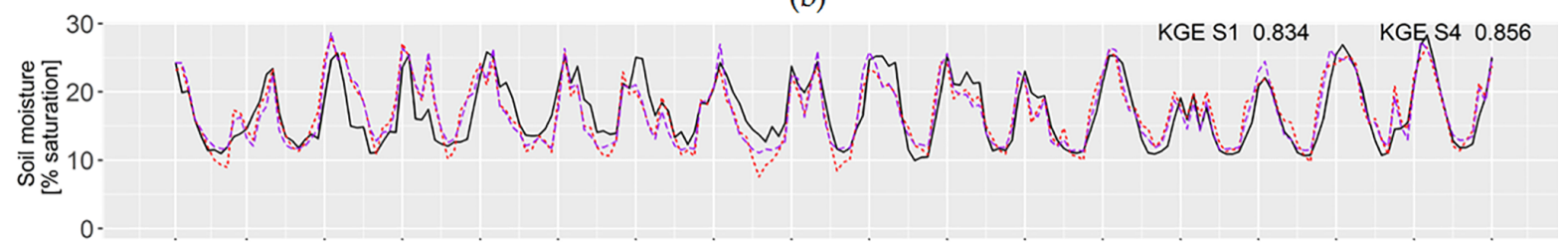

(c)

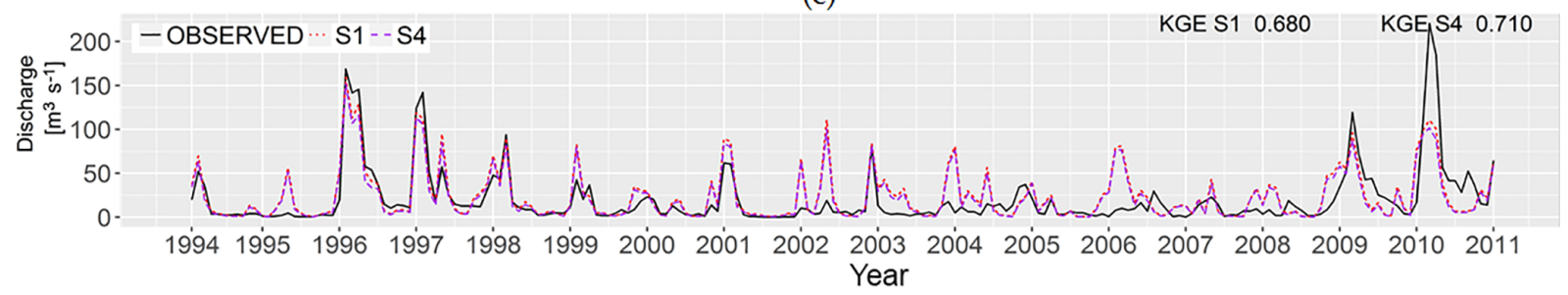

Figure 8. (a) Monthly GLEAM actual evapotranspiration (black) and estimated actual evapotranspiration (red and purple) time series over the entire Oum er Rbia basin. (b) Monthly ESA CCI soil moisture (black) and estimated soil moisture (red and purple) time series over the entire Oum er Rbia basin. (c) Monthly observed discharge (black) and estimated discharge (red and purple) time series at Mechra Eddahk. The red dashed lines represent estimates from calibration scenario S1. The purple dashed lines represent the calibrated time series from calibration scenario S4 which are taken from the runs that yield the best simulations. Estimated time series over the entire Oum er Rbia basin for the validation time period obtained with MSWEP precipitation are shown.

$\mathrm{KGE}_{q}$ and $\mathrm{NSE}_{q}$ increases and $\mathrm{PBias}_{q}$ decreases were obtained when the model was calibrated using only soil moisture (S3) and using the combination of evapotranspiration and soil moisture (S4), but larger improvements in $r_{q}$ were obtained with the step-wise calibration scenario (S4). The gains in $\mathrm{KGE}_{q}, \mathrm{NSE}_{q}$ and $r_{q}$ when comparing calibration scenarios S2 and S0 were positive, but of a lower magnitude than when the model was calibrated in scenarios S3 and S4. The higher performance of scenario S4 may be due to the fact that this calibration approach used multiple system variables providing more hydrological information and allowing the identification of more parameters than when those variables were separately used.

In each bar plot of Fig. 9, metrics improvements were larger at Ait Ouchene station than at Mechra Eddahk station. This is due to the lower discharge performance for the reference calibration scenario S0 at the former gauging location. Note that in some cases the change in $\mathrm{KGE}_{q}$ was negative (e.g. when EI precipitation was used at Ait Ouchene station) because although there was an improvement in the $\mathrm{KGE}_{q}$ performance indicator during the calibration time period, when calculating it for the validation time period, it is possible that the metric slightly worsened. Note that some variations in $\mathrm{NSE}_{q}, \mathrm{PBias}_{q}$ and $r_{q}$ were small or close to 0 because its calibration was optimized for $\mathrm{KGE}_{q}$ and not for those particular metrics in terms of discharge. A possi- ble route to overcome this problem may be to use different performance indicators (for example, KGE, NSE, PBias and $r$ ) as objective functions to optimize in each calibration scenario, instead of using a single one. This multi-objective calibration approach may further improve discharge model estimates.

\section{Discussion and conclusions}

This study investigated alternative routes to calibrate the large-scale hydrological model PCR-GLOBWB using Earth observations globally available for the data-poor river basin of Oum er Rbia in Morocco. Three global precipitation products, EI, WFDEI and MSWEP, were inter-compared and applied to force PCR-GLOBWB. Five different calibration scenarios were followed where GLEAM actual evapotranspiration and ESA CCI surface soil moisture data were used to identify model parameters with the aim to improve discharge estimates. In situ discharge observations were also used for calibration, as they are traditionally used to calibrate hydrological models. 

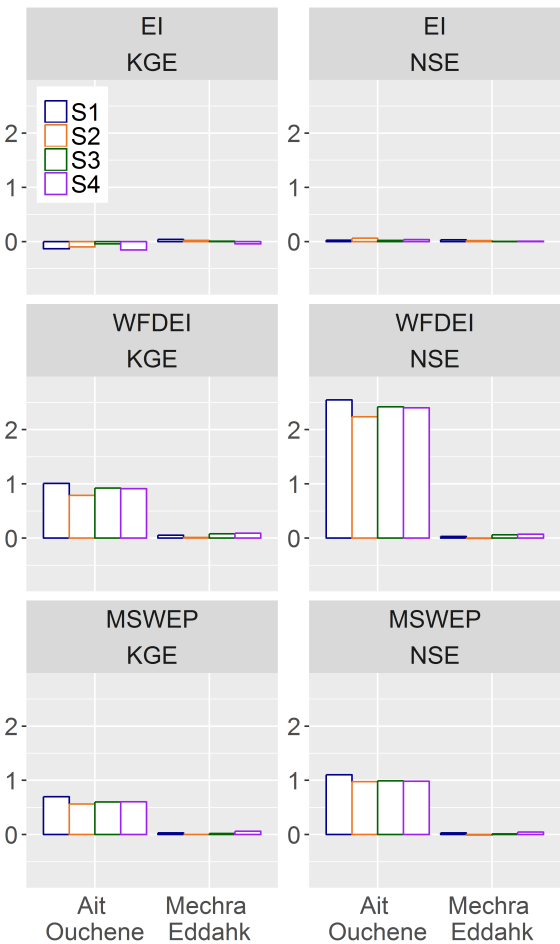
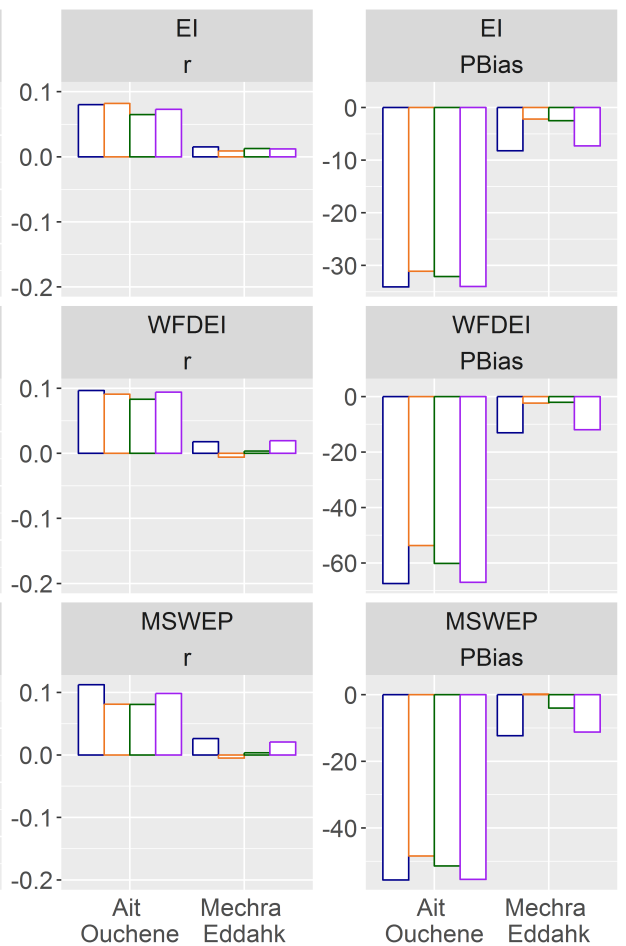

Figure 9. KGE, NSE, $r$ and PBias variations comparing monthly discharge estimates of calibration scenarios S1, S2, S3 and S4 with S0. Rows indicate the three global precipitation products and columns indicate the performance metrics.

Results showed that GLEAM actual evapotranspiration and ESA CCI soil moisture observations may be used to calibrate determined PCR-GLOBWB model parameters. GLEAM actual evapotranspiration was used to calibrate the reference potential evapotranspiration $\left(f_{\mathrm{e}}\right)$ as expected, affecting the water exchange between the top soil layer and the atmosphere and hence the soil water balance. ESA CCI soil moisture data was used to calibrate the minimum soil water capacity $\left(f_{\mathrm{w}}\right)$ and the saturated hydraulic conductivities of the soil layers $\left(f_{k}\right)$, determining the surface runoff generation response, the shallow sub-surface flow and the groundwater recharge. However, calibration using only GLEAM evapotranspiration or only ESA CCI soil moisture data can result in multiple parameter combinations being optimal in terms of discharge (over-parametrization or equifinality problem). To overcome this problem, a step-wise calibration scenario based on both observations, evapotranspiration and soil moisture was necessary to identify the optimal values of reference potential evapotranspiration $\left(f_{\mathrm{e}}\right)$, runoffinfiltration partitioning parameters $\left(f_{\mathrm{w}}\right)$ and the soil saturated hydraulic conductivity $\left(f_{k}\right)$. Nonetheless, neither of these observations were used to calibrate the baseflow from the active groundwater layer $\left(f_{j}\right)$. To identify baseflow recession coefficient parameter $\left(f_{j}\right)$, a multi-objective calibration approach to streamflow observations could be followed. Similarly to Fenicia et al. (2007), multiple objective functions may be optimized in sequential steps for high flows, low flows and timing.

Spatially uniform pre-factors for the entire Oum er Rbia basin were used for the variation of the parameter values in this study. Developing novel calibration strategies where prefactors, and thus model parameters, vary with soil type, land use, elevation and/or other characteristics within the basin would be a promising research route to investigate. Furthermore, the present work inter-compares five calibration scenarios using a brute force method, where several combinations of parameters values were tested and the best performing was selected. For these combinations, and due to computational limitations, only four pre-factors were considered leading to 81 model runs per precipitation product. Using more pre-factor values and therefore, more runs may improve the estimation of the optimal parameters set for each calibration scenario. A suggestion for future studies is to use an ensemble Kalman filter to calibrate the hydrological model, as previously presented in literature (Moradkhani et al., 2005; Wanders et al., 2014). Furthermore, the validation of this study was carried out exclusively on streamflow. Other validation approaches, including the empirical orthogonal functions, wavelet analysis or their combination, may be another promising way towards a more in-depth validation of distributed hydrological models (Mascaro et al., 2015; Koch et al., 2015; Fang et al., 2015). 
A step-wise calibration approach based on GLEAM actual evapotranspiration and ESA CCI soil moisture resulted in discharge estimates of acceptable accuracy (Moriasi et al., 2007), compared to discharge estimates derived from a model that was calibrated to in situ discharge measurements. Traditional calibration to in situ discharge measurements resulted in the highest model performance. A model calibrated only on evapotranspiration or soil moisture observations achieved a lower discharge performance than when they were used together.

In the inter-comparison among the three global precipitation products, WFDEI showed the worst performance, whereas EI and MSWEP performed quite well. Apart from the in situ discharge calibration scenario, the highest discharge improvement was obtained when the two latter forcing data were used in combination with a step-wise calibration approach based on evapotranspiration and soil moisture observations.

Results indicated that the precipitation impact on streamflow estimates was more significant than the one derived from calibrating model parameters; thus, the lower quality of WFDEI compared to EI and MSWEP decreased model performance and calibration was biased in order to compensate precipitation errors. Further investigation of the effect of precipitation errors on model efficiency, and also on model parameters estimation may be an interesting route for hydrological research (Andréassian et al., 2004; Looper et al., 2012).

Although there is still room for further research, this study showed that globally available Earth observations, such as evapotranspiration or soil moisture, can be used to further parameterize large-scale hydrological models providing reasonable discharge estimates at the regional or basin scales. In principle, these calibration approaches can be applied and investigated in other basins without or with limited in situ ground hydro-meteorological data (ungauged basins), to not only estimate discharge, but also to improve the understanding of the hydrological processes in the basin. Results suggested the potential of using other satellite products for hydrological modelling studies, including soil moisture products such as AMSR-E (Njoku et al., 2003) and SMOS (Kerr et al., 2001), evapotranspiration products such as SEBAL (Bastiaanssen et al., 1998) and MOD16 (Nishida, 2003), total water storage products such as GRACE (Tapley et al., 2004), etc. The spatial information of these satellite-based products could be used in a different way than the one explained in this study. For example, a calibration scenario based on a pixel-by-pixel, instead of basin-average, comparison of surface soil moisture and actual evapotranspiration model estimates and observations could further improve discharge estimates. This calibration approach would have to take into account the spatial variability of the variables over the basin. Previous studies investigated how to incorporate spatial information into hydrological models using innovative spatial performance metrics to analyse the spatial sensitivity of simulated land-surface patterns (Koch et al., 2017).

Future studies may investigate step-wise calibration approaches using the combined information from multiple hydrological system variables. By incorporating several data products, different parts or components of the model can be optimized to increase the overall model performance. Another approach could be to calibrate the model to different variables with multiple objective functions - multi-objective calibration (Gupta et al., 1998; Khu and Madsen, 2005; Fenicia et al., 2007). Alternatively, these hydro-meteorological data which are globally available may be used to identify and develop relationships between different basins using similarities, classification and scaling frameworks, as presented in previous studies (Samaniego et al., 2010; Kumar et al., 2013).

Data availability. The location and availability of all the data (meteorological forcing, satellite-based soil moisture and evapotranspiration and ground discharge) and assets (PCR-GLOBWB - Sutanudjaja et al., 2016, 2017; E2O downscaling tools - Schellekens and Weiland, 2017) used for this research are indicated in the paper, including references and links to repositories. 


\section{Appendix A}

(a)

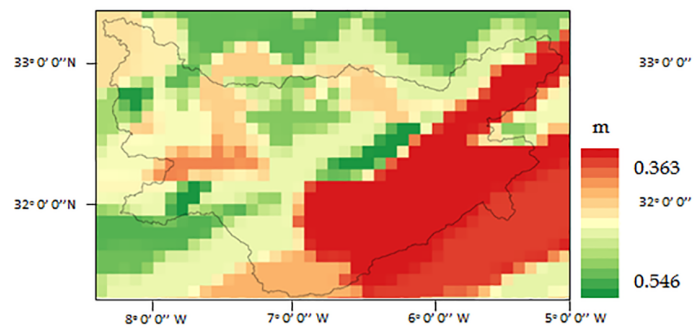

(c)

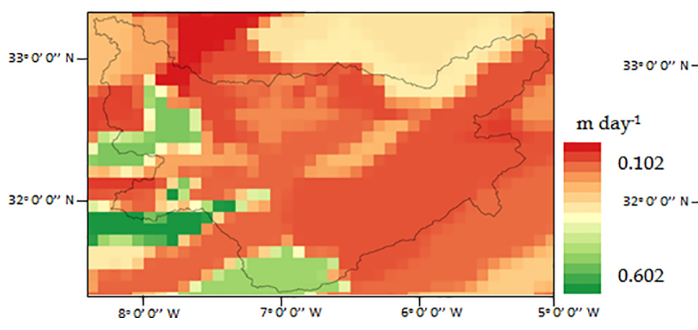

(b)

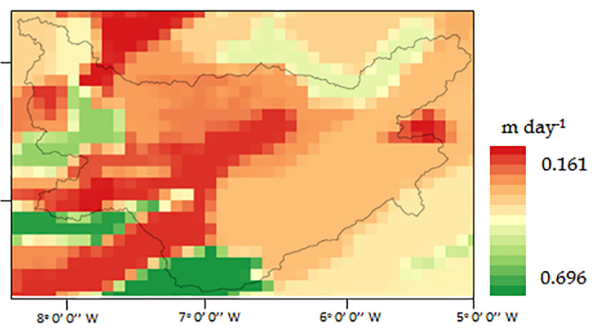

(d)

Figure A1. Initial model parameter values for the $\mathrm{S} 0$ calibration scenario (reference): (a) total soil water storage capacity $\left(W_{\max }=\mathrm{SC}_{1}+\right.$ $\left.\mathrm{SC}_{2}+\mathrm{SC}_{3}\right)$, (b) saturated hydraulic conductivity of the first and second soil layers $\left(K_{\mathrm{sat} 1}\right.$ and $\left.K_{\mathrm{sat} 2}\right)$, (c) saturated hydraulic conductivity of third soil layer $\left(K_{\text {sat3 }}\right)$ and $(\mathbf{d})$ baseflow recession coefficient $(J)$. 


\section{The Supplement related to this article is available online at https://doi.org/10.5194/hess-21-3125-2017- supplement.}

Competing interests. The authors declare that they have no conflict of interest.

Acknowledgements. This research received funding from the European Union Seventh Framework Programme (FP7/2007-2013) under grant agreement no. 603608, Global Earth Observation for integrated water resource assessment: eartH2Observe. We would like to thank ICARDA for their engagement and collaboration during this work. For the discharge data, we are very grateful to Yves Tramblay from the Institut de Recherche pour le Developpement (IRD) in France and El Mahdi El Khalki and Lahoucine Hanich from the Laboratoire de Géoressources, Département des Sciences de la Terre, Faculté des Sciences et Techniques, Université Cadi Ayyad in Marrakech, Morocco. For the GLEAM evapotranspiration data, we would like to thank VU Amsterdam, the Netherlands and Ghent University, Belgium. For the ESA CCI soil moisture, we are indebted to the Vienna University of Technology, Austria. The authors would also like to thank Markus Hrachowitz, Remko C. Nijzink and Heye Bogena, who helped to improve this paper considerably.

Edited by: Markus Hrachowitz

Reviewed by: Remko C. Nijzink and Heye Bogena

\section{References}

Andréassian, V., Perrin, C., and Michel, C.: Impact of imperfect potential evapotranspiration knowledge on the efficiency and parameters of watershed models, J. Hydrol., 286, 19-35, 2004.

Bastiaanssen, W., Menenti, M., Feddes, R., and Holtslag, A.: A remote sensing surface energy balance algorithm for land (SEBAL). 1. Formulation, J. Hydrol., 212, 198-212, 1998.

Beck, H. E., de Jeu, R. A., Schellekens, J., van Dijk, A. I., and Bruijnzeel, L. A.: Improving curve number based storm runoff estimates using soil moisture proxies, IEEE J. Sel. Top. Appl., 2, 250-259, 2009.

Beck, H. E., van Dijk, A. I., de Roo, A., Miralles, D. G., McVicar, T. R., Schellekens, J., and Bruijnzeel, L. A.: Global-scale regionalization of hydrologic model parameters, Water Resour. Res., 52, 3599-3622, https://doi.org/10.1002/2015WR018247, 2016.

Beck, H. E., van Dijk, A. I. J. M., Levizzani, V., Schellekens, J., Miralles, D. G., Martens, B., and de Roo, A.: MSWEP: 3hourly $0.25^{\circ}$ global gridded precipitation (1979-2015) by merging gauge, satellite, and reanalysis data, Hydrol. Earth Syst. Sci., 21, 589-615, https://doi.org/10.5194/hess-21-589-2017, 2017.

Bouchaou, L., Michelot, J., Qurtobi, M., Zine, N., Gaye, C., Aggarwal, P., Marah, H., Zerouali, A., Taleb, H., and Vengosh, A.: Origin and residence time of groundwater in the Tadla basin (Morocco) using multiple isotopic and geochemical tools, J. Hydrol., $379,323-338,2009$.
Brocca, L., Moramarco, T., Melone, F., Wagner, W., Hasenauer, S., and Hahn, S.: Assimilation of surface-and root-zone ASCAT soil moisture products into rainfall-runoff modeling, IEEE T. Geosci. Remote, 50, 2542-2555, 2012.

Campo, L., Caparrini, F., and Castelli, F.: Use of multi-platform, multi-temporal remote-sensing data for calibration of a distributed hydrological model: an application in the Arno basin, Italy, Hydrol. Process., 20, 2693-2712, 2006.

Dee, D. P., Uppala, S. M., Simmons, A. J., Berrisford, P., Poli, P., Kobayashi, S., Andrae, U., Balmaseda, M. A., Balsamo, G., Bauer, P., Bechtold, P., Beljaars, A. C. M., van de Berg, L., Bidlot, J., Bormann, N., Delsol, C., Dragani, R., Fuentes, M., Geer, A. J., Haimberger, L., Healy, S. B., Hersbach, H., Hólm, E. V., Isaksen, L., Kållberg, P., Köhler, M., Matricardi, M., McNally, A. P., Monge-Sanz, B. M., Morcrette, J.-J., Park, B.-K., Peubey, C., de Rosnay, P., Tavolato, C., Thépaut, J.-N., and Vitart, F.: The ERA-Interim reanalysis: Configuration and performance of the data assimilation system, Q. J. Roy. Meteor. Soc., 137, 553-597, 2011.

Dorigo, W., Gruber, A., De Jeu, R., Wagner, W., Stacke, T., Loew, A., Albergel, C., Brocca, L., Chung, D., Parinussa, R., and Kidd R.: Evaluation of the ESA CCI soil moisture product using ground-based observations, Remote Sens. Environ., 162, 380395, 2015.

Draper, C. S., Walker, J. P., Steinle, P. J., De Jeu, R. A. M., and Holmes, T. R. H.: An evaluation of AMSR-E derived soil moisture over Australia, Remote Sens. Environ., 113, 703-710, https://doi.org/10.1016/j.rse.2008.11.011, 2009.

Fang, Z., Bogena, H., Kollet, S., Koch, J., and Vereecken, H.: Spatio-temporal validation of long-term 3D hydrological simulations of a forested catchment using empirical orthogonal functions and wavelet coherence analysis, J. Hydrol., 529, 1754 1767, 2015.

Fenicia, F., Savenije, H. H., Matgen, P., and Pfister, L.: A comparison of alternative multiobjective calibration strategies for hydrological modeling, Water Resour. Res., 43, W03434, https://doi.org/10.1029/2006WR005098, 2007.

Gupta, H. V., Sorooshian, S., and Yapo, P. O.: Toward improved calibration of hydrologic models: Multiple and noncommensurable measures of information, Water Resour. Res., 34, 751-763, 1998.

Gupta, H. V., Wagener, T., and Liu, Y.: Reconciling theory with observations: elements of a diagnostic approach to model evaluation, Hydrol. Process., 22, 3802-3813, 2008.

Gupta, H. V., Kling, H., Yilmaz, K. K., and Martinez, G. F.: Decomposition of the mean squared error and NSE performance criteria: Implications for improving hydrological modelling, J. Hydrol., 377, 80-91, 2009.

Hafeez, M., van de Giesen, N., Bardsley, E., Seyler, F., Pail, R., and Taniguchi, M.: GRACE, remote sensing and ground-based methods in multi-scale hydrology: proceedings of symposium JHO1 held during IUGG2011, IAHS Publications, 2011.

Hagemann, S. and Gates, L. D.: Improving a subgrid runoff parameterization scheme for climate models by the use of high resolution data derived from satellite observations, Clim. Dynam., 21, 349-359, 2003.

Houdret, A.: Les conflits autour de l'eau au Maroc: origines sociopolitiques et écologiques et perspectives pour transformation des conflits, Thèse de doctorat: Sciences politiques, Universität Duisburg-Essen, 72 pp., 2008. 
Hrachowitz, M., Savenije, H. H. G., Blöschl, G., McDonnell, J. J., Sivapalan, M., Pomeroy, J. W., Arheimer, B., Blume, T., Clark, M. P., Ehret, U., Fenicia, F., Freer, J. E., Gelfan, A., Gupta, H. V., Hughes, D. A., Hut, R. W., Montanari, A., Pande, S., Tetzlaff, D., Troch, P. A., Uhlenbrook, S., Wagener, T., Winsemius, H. C., Woods, R. A., Zehe, E., and Cudennec, C.: A decade of Predictions in Ungauged Basins (PUB) - a review, Hydrolog. Sci. J., 58, 1198-1255, 2013.

Huffman, G. J., Bolvin, D. T., Nelkin, E. J., Wolff, D. B., Adler, R. F., Gu, G., Hong, Y., Bowman, K. P., and Stocker, E. F.: The TRMM multisatellite precipitation analysis (TMPA): Quasiglobal, multiyear, combined-sensor precipitation estimates at fine scales, J. Hydrometeorol., 8, 38-55, 2007.

Immerzeel, W. and Droogers, P.: Calibration of a distributed hydrological model based on satellite evapotranspiration, J. Hydrol., 349, 411-424, 2008.

Isenstein, E. M., Wi, S., Yang, Y. E., and Brown, C.: Calibration of a distributed hydrologic model using streamflow and remote sensing snow data, in: World Environmental and Water Resources Congress 2015, ASCE, 973-982, 2015.

Jacobs, J. M., Myers, D. A., and Whitfield, B. M.: Improved rainfall/runoff estimates using remotely sensed soil moisture, J. Am. Water Resour. As., 39, 313-324, 2003.

Jones, A., Breuning-Madsen, H., Brossard, M., Dampha, A., Deckers, J., Dewitte, O., Gallali, T., Hallett, S., Jones, R., Kilasara, M., Le Roux, P., Micheli, E., Montanarella, L., Spaargaren, O., Thiombiano, L., Van Ranst, E., Yemefack, M., and Zougmoré, R.: Soil Atlas of Africa, European Commission, Luxembourg, https://doi.org/10.2788/52319, 2013.

Joyce, R. J., Janowiak, J. E., Arkin, P. A., and Xie, P.: CMORPH: A method that produces global precipitation estimates from passive microwave and infrared data at high spatial and temporal resolution, J. Hydrometeorol., 5, 487-503, 2004.

Kerr, Y. H., Waldteufel, P., Wigneron, J.-P., Martinuzzi, J., Font, J., and Berger, M.: Soil moisture retrieval from space: The Soil Moisture and Ocean Salinity (SMOS) mission, IEEE T. Geosci. Remote, 39, 1729-1735, 2001.

Khu, S. T. and Madsen, H.: Multiobjective calibration with Pareto preference ordering: An application to rainfallrunoff model calibration, Water Resour. Res., 41, W03004, https://doi.org/10.1029/2004WR003041, 2005.

Kite, G. and Droogers, P.: Comparing evapotranspiration estimates from satellites, hydrological models and field data, J. Hydrol., 229, 3-18, 2000.

Koch, J., Jensen, K. H., and Stisen, S.: Toward a true spatial model evaluation in distributed hydrological modeling: Kappa statistics, Fuzzy theory, and EOF-analysis benchmarked by the human perception and evaluated against a modeling case study, Water Resour. Res., 51, 1225-1246, 2015.

Koch, J., Mendiguren, G., Mariethoz, G., and Stisen, S.: Spatial sensitivity analysis of simulated land-surface patterns in a catchment model using a set of innovative spatial performance metrics, J. Hydrometeorol., 18, 1121-1142, https://doi.org/10.1175/JHMD-16-0148.1, 2017.

Kumar, R., Samaniego, L., and Attinger, S.: Implications of distributed hydrologic model parameterization on water fluxes at multiple scales and locations, Water Resour. Res., 49, 360-379, 2013.
Liu, Y., Dorigo, W. A., Parinussa, R., de Jeu, R. A., Wagner, W., McCabe, M. F., Evans, J., and Van Dijk, A.: Trend-preserving blending of passive and active microwave soil moisture retrievals, Remote Sens. Environ., 123, 280-297, 2012.

Liu, Y. Y., Parinussa, R. M., Dorigo, W. A., De Jeu, R. A. M., Wagner, W., van Dijk, A. I. J. M., McCabe, M. F., and Evans, J. P.: Developing an improved soil moisture dataset by blending passive and active microwave satellite-based retrievals, Hydrol. Earth Syst. Sci., 15, 425-436, https://doi.org/10.5194/hess-15425-2011, 2011.

Lo, M.-H., Famiglietti, J. S., Yeh, P.-F., and Syed, T.: Improving parameter estimation and water table depth simulation in a land surface model using GRACE water storage and estimated base flow data, Water Resour. Res., 46, W05517, https://doi.org/10.1029/2009WR007855, 2010.

Looper, J. P., Vieux, B. E., and Moreno, M. A.: Assessing the impacts of precipitation bias on distributed hydrologic model calibration and prediction accuracy, J. Hydrol., 418, 110-122, 2012.

López López, P., Wanders, N., Schellekens, J., Renzullo, L. J., Sutanudjaja, E. H., and Bierkens, M. F. P.: Improved large-scale hydrological modelling through the assimilation of streamflow and downscaled satellite soil moisture observations, Hydrol. Earth Syst. Sci., 20, 3059-3076, https://doi.org/10.5194/hess-20-30592016, 2016.

Loukas, A. and Vasiliades, L.: Streamflow simulation methods for ungauged and poorly gauged watersheds, Nat. Hazards Earth Syst. Sci., 14, 1641-1661, https://doi.org/10.5194/nhess14-1641-2014, 2014.

Martens, B., Miralles, D., Lievens, H., Fernández-Prieto, D., and Verhoest, N.: Improving terrestrial evaporation estimates over continental Australia through assimilation of SMOS soil moisture, Int. J. Appl. Earth Obs., 48, 146-162, 2016 a.

Martens, B., Miralles, D., Lievens, H., van der Schalie, R., de Jeu, R., Fernández-Prieto, D., and Verhoest, N.: GLEAM v3: updated land evaporation and root-zone soil moisture datasets, in: EGU General Assembly Conference Abstracts, vol. 18, p. 4253, $2016 b$.

Mascaro, G., Vivoni, E. R., and Méndez-Barroso, L. A.: Hyperresolution hydrologic modeling in a regional watershed and its interpretation using empirical orthogonal functions, Adv. Water Resour., 83, 190-206, 2015.

Miralles, D. G., De Jeu, R. A. M., Gash, J. H., Holmes, T. R. H., and Dolman, A. J.: Magnitude and variability of land evaporation and its components at the global scale, Hydrol. Earth Syst. Sci., 15, 967-981, https://doi.org/10.5194/hess-15-967-2011, 2011a.

Miralles, D. G., Holmes, T. R. H., De Jeu, R. A. M., Gash, J. H., Meesters, A. G. C. A., and Dolman, A. J.: Global land-surface evaporation estimated from satellite-based observations, Hydrol Earth Syst. Sci., 15, 453-469, https://doi.org/10.5194/hess-15453-2011, 2011b.

Moradkhani, H., Sorooshian, S., Gupta, H. V., and Houser, P. R.: Dual state-parameter estimation of hydrological models using ensemble Kalman filter, Adv. Water Resour., 28, 135-147, 2005.

Moriasi, D. N., Arnold, J. G., Van Liew, M. W., Bingner, R. L., Harmel, R. D., and Veith, T. L.: Model evaluation guidelines for systematic quantification of accuracy in watershed simulations, T. ASABE, 50, 885-900, 2007. 
Nash, J. E. and Sutcliffe, J. V.: River flow forecasting through conceptual models part I - A discussion of principles, J. Hydrol., 10, 282-290, 1970.

New, M., Lister, D., Hulme, M., and Makin, I.: A high-resolution data set of surface climate over global land areas, Clim. Res., 21, 1-25, 2002.

Nishida, K.: Validation of prototype MODIS evapotranspiration (MOD16) in the eastern Asia, in: AGU Fall Meeting Abstracts, http://adsabs.harvard.edu/abs/2003AGUFM.B21E0765N (last access: 28 of May 2017), 2003.

Njoku, E. G., Jackson, T. J., Lakshmi, V., Chan, T. K., and Nghiem, S. V.: Soil moisture retrieval from AMSR-E, IEEE T. Geosci. Remote, 41, 215-229, 2003.

Ouatiki, H., Boudhar, A., Tramblay, Y., Jarlan, L., Benabdelouhab, T., Hanich, L., El Meslouhi, M. R., and Chehbouni, A.: Evaluation of TRMM 3B42 V7 Rainfall Product over the Oum Er Rbia Watershed in Morocco, Climate, 5, 1, https://doi.org/10.3390/cli5010001, 2017.

Parajka, J., Naeimi, V., Blöschl, G., Wagner, W., Merz, R., and Scipal, K.: Assimilating scatterometer soil moisture data into conceptual hydrologic models at the regional scale, Hydrol. Earth Syst. Sci., 10, 353-368, https://doi.org/10.5194/hess-10353-2006, 2006.

Pearson, K.: Mathematical Contributions to the Theory of Evolution - On a Form of Spurious Correlation Which May Arise When Indices Are Used in the Measurement of Organs, P. R. Soc. London, 60, 489-498, 1896.

Reichle, R. H. and Koster, R. D.: Bias reduction in short records of satellite soil moisture, Geophys. Res. Lett., 31, L19501, https://doi.org/10.1029/2004GL020938, 2004.

Rientjes, T., Muthuwatta, L. P., Bos, M., Booij, M., and Bhatti, H.: Multi-variable calibration of a semi-distributed hydrological model using streamflow data and satellite-based evapotranspiration, J. Hydrol., 505, 276-290, 2013.

Roy, A., Royer, A., and Turcotte, R.: Improvement of springtime streamflow simulations in a boreal environment by incorporating snow-covered area derived from remote sensing data, J. Hydrol., 390, 35-44, 2010.

Samaniego, L., Kumar, R., and Attinger, S.: Multiscale parameter regionalization of a grid-based hydrologic model at the mesoscale, Water Resour. Res., 46, W05523, https://doi.org/10.1029/2008WR007327, 2010.

Schellekens, J. and Weiland, F. S.: earth2observe/downscaling-tools: 2017.2 Pre-release, https://doi.org/10.5281/zenodo.545779, 2017.

Seibert, J. and Beven, K. J.: Gauging the ungauged basin: how many discharge measurements are needed?, Hydrol. Earth Syst. Sci., 13, 883-892, https://doi.org/10.5194/hess-13-883-2009, 2009.

Seneviratne, S. I., Corti, T., Davin, E. L., Hirschi, M., Jaeger, E. B., Lehner, I., Orlowsky, B., and Teuling, A. J.: Investigating soil moisture-climate interactions in a changing climate: A review, Earth-Sci. Rev., 99, 125-161, 2010.

Sivapalan, M., Takeuchi, K., Franks, S., Gupta, V. K., Karambiri, H., Lakshimi, V., Liang, X., McDonnell, J. J., Mendiondo, E. M., O'Connell, P. E., Oki, T., Pomeroy, J. W., Schertzer, D., Uhlenbrook, S., and Zehe, E.: IAHS Decade on Predictions in Ungauged Basins (PUB), 2003-2012: Shaping an exciting future for the hydrological sciences, Hydrolog. Sci. J., 48, 857-880, 2003.
Sutanudjaja, E. H., van Beek, L. P. H., de Jong, S. M., van Geer, F. C., and Bierkens, M. F. P.: Large-scale groundwater modeling using global datasets: a test case for the Rhine-Meuse basin, Hydrol. Earth Syst. Sci., 15, 2913-2935, https://doi.org/10.5194/hess-15-2913-2011, 2011.

Sutanudjaja, E., Van Beek, L., De Jong, S., Van Geer, F., and Bierkens, M.: Calibrating a large-extent high-resolution coupled groundwater-land surface model using soil moisture and discharge data, Water Resour. Res., 50, 687-705, 2014.

Sutanudjaja, E., van Beek, R., Wada, Y., Bosmans, J., Drost, N., de Graaf, I., de Jong, K., Lopez Lopez, P., Pessenteiner, S., Oliver, S., Straatsma, M., Wanders, N., Wisser, D., and Bierkens, M.: PCR-BLOBWB_model, Zenodo, https://doi.org/10.5281/zenodo.60764, 2016.

Sutanudjaja, E., van Beek, R., Wada, Y., Bosmans, J., Drost, N., de Graaf, I., de Jong, K., Lopez Lopez, P., Pessenteiner, S., Oliver, S., Straatsma, M., Wanders, N., Wisser, D., and Bierkens, M.: PCR-BLOBWB_model, available at: https://github.com/ UU-Hydro/PCR-GLOBWB_model, last access: 17 April 2017.

Tapley, B. D., Bettadpur, S., Watkins, M., and Reigber, C.: The gravity recovery and climate experiment: Mission overview and early results, Geophys. Res. Lett., 31, L09607, https://doi.org/10.1029/2004GL019920, 2004.

Thirel, G., Salamon, P., Burek, P., and Kalas, M.: Assimilation of MODIS snow cover area data in a distributed hydrological model using the particle filter, Remote Sensing, 5, 5825-5850, 2013.

Tramblay, Y., Bouaicha, R., Brocca, L., Dorigo, W., Bouvier, C., Camici, S., and Servat, E.: Estimation of antecedent wetness conditions for flood modelling in northern Morocco, Hydrol. Earth Syst. Sci., 16, 4375-4386, https://doi.org/10.5194/hess-16-43752012, 2012.

Tramblay, Y., Thiemig, V., Dezetter, A., and Hanich, L.: Evaluation of satellite-based rainfall products for hydrological modelling in Morocco, Hydrolog. Sci. J., 61, 2509-2519, 2016.

van Beek, L., Wada, Y., and Bierkens, M. F.: Global monthly water stress: 1. Water balance and water availability, Water Resour. Res., 47, W07517, https://doi.org/10.1029/2010WR009791, 2011.

Vereecken, H., Huisman, J., Bogena, H., Vanderborght, J., Vrugt, J., and Hopmans, J.: On the value of soil moisture measurements in vadose zone hydrology: A review, Water Resour. Res., 44, W00D06, https://doi.org/10.1029/2008WR006829, 2008.

Wanders, N., Bierkens, M. F., de Jong, S. M., de Roo, A., and Karssenberg, D.: The benefits of using remotely sensed soil moisture in parameter identification of large-scale hydrological models, Water Resour. Res., 50, 6874-6891, 2014.

Weedon, G. P., Balsamo, G., Bellouin, N., Gomes, S., Best, M. J., and Viterbo, P.: The WFDEI meteorological forcing data set: WATCH Forcing Data methodology applied to ERA-Interim reanalysis data, Water Resour. Res., 50, 7505-7514, 2014.

Weiland, F. S., Lopez, P., Van Dijk, A., and Schellekens, J.: Global high-resolution reference potential evaporation, in: MODSIM 2015, Conference Proceedings, Broadbeach, Queensland, Australia, 2015.

Winsemius, H., Schaefli, B., Montanari, A., and Savenije, H.: On the calibration of hydrological models in ungauged basins: A framework for integrating hard and soft hydrological information, Water Resour. Res., 45, W12422, https://doi.org/10.1029/2009WR007706, 2009. 